Chapter 13

\title{
Conducting Polymer Nanocomposites for Anticorrosive and Antistatic Applications
}

\author{
Hema Bhandari, S. Anoop Kumar and S. K. Dhawan \\ Additional information is available at the end of the chapter \\ http://dx.doi.org/10.5772/50470
}

\section{Introduction}

Intrinsically conducting polymers (ICPs) have been considered for use in various applications. One of the most important applications of these materials which are attracting considerable attention in the most recent times is in corrosion protection of oxidizable metals [1]. The effective use of conducting polymers for corrosion protection of metals can be carried out by different methods; like formulation of polymers with paints, by electro-deposition of conducting polymers onto metal surface and by direct addition of polymers in the corrosive solution as corrosion inhibitors. Coatings on the surface of metals by polymeric materials have been widely used in industries for the protection of these materials against corrosion [2-13]. Some specific conducting polymers like polyaniline and its derivatives, have been found to display interesting corrosion protection properties. In the past decade, the use of polyaniline as anticorrosion coatings had been explored as the potential candidates to replace the chromium-containing materials, which have adverse health and environmental concerns [14-17]. A polymer behaves as a barrier when it exists in the electronically and ionically insulating state. An important feature of the polymer coating in its conductive state is the ability to store large quantity of charge at the interface formed with a passive layer on a metal. This charge can be effectively used to oxidize base metal to form a passive layer. Thus, the conducting polymer film was also capable of maintaining a stationary potential of the protected metal in the passive range [18]. Application of conducting polymers like polyaniline to corrosion protection of metals is, however, subject to some limitations. First, charge stored in the polymer layer (used to oxidize base metal and to produce passive layer) can be irreversibly consumed during the system's redox reactions. Consequently, protective properties of the polymer coating may be lost with time. Also, porosity and anion exchange properties of conducting polymers could be disadvantageous, particularly when it comes to 
pitting corrosion caused by small aggressive anions (e.g., chlorides) [19]. An interesting alternative is to consider conducting polymer based composite systems. Composite materials play an important role due to their light weight and improved corrosion resistance. These materials usually comprise of a polymer matrix in which fibres and/or small filler particles are thoroughly dispersed. Silicon dioxide particles, for example, comprise one of the common fillers in composite materials such as plastics and films. Conducting polyaniline/inorganic nanocomposites have also attracted more and more attention. A number of different metals and metal oxide particles have so far been encapsulated into the shell of conducting PANI to produce a host of composites materials. These composite materials have shown better mechanical, physical and chemical properties, due to combining the qualities of conducting PANI and inorganic particles [20-22]. Among various inorganic particles, $\mathrm{SiO}_{2}$ nanoparticles have attractive attention due to their excellent reinforcing properties for polymer materials [23]. However, $\mathrm{SiO}_{2}$ is an insulator and a lot of works have been done to expand the applications of insulator $\mathrm{SiO}_{2}$ as fillers and improve the processability of polyaniline [24-28]. Corrosion protective coatings on the mild steel surface by electrochemical deposition of conducting polymers have been extensively studied [29-33]. These types of coatings lack long lasting ability of metals in a corrosive medium. In order to improve the adherence ability and efficiency of conducting polymer coating on the metal surface, the use of liquids paints have also been performed by many researchers [34-38]

Present chapter is based on the preparation of conducting polymer nanocomposites coating onto the mild steel surface by using powder coating techniques. Powder coatings are often used as an alternation to liquids paints finishing or traditional liquid finishing. The key benefits of powder coating techniques are cost effective, environmentally friendly, excellence of finish and performance. This shows single coat finishes with no primer or any other solvent required and high film thickness can be achieved with single coat. Preparation of $\mathrm{PANI} / \mathrm{SiO}_{2}$ nanocomposites was carried out using in-situ polymerization and evaluation of corrosion protection effect for the polyaniline $/ \mathrm{SiO}_{2}$ nanocomposite materials on the mild steel surface. Corrosion protection performance of these composites was compared with that of the polyaniline by performing a series of electrochemical measurements of corrosion potential, polarization resistance, and corrosion current in $1.0 \mathrm{M} \mathrm{HCl}$ solution.

In order to improve anticorrosion performance of mid steel in $3.5 \% \mathrm{NaCl}$ aqueous medium, preparation of highly hydrophobic polyaniline- $\mathrm{SiO}_{2}$ nano-composite coating have also been developed. There are several ways to develop hydrophobic surfaces i.e. by electrodeposition method [39-41], solvent casting of polymers [42], layer-by-layer deposition [43-45], chemical vapor deposition [46, 47], dip-coating and/or self-assembly [48-51] and chemical grafting [52-55]. Most of those methods cannot be easily developed and they need very strict conditions of preparation, and low adhesion coatings are often obtained. However, development of highly hydrophobic conducting polymer nanocomposite coatings via powder coating method was found to be highly adhesive, long lasting and more convenient $[56,57]$. 


\section{Corrosion study}

The corrosion inhibition performance study was carried out at room temperature in aqueous solution of $1.0 \mathrm{M} \mathrm{HCl} / 3.5 \% \mathrm{NaCl}$ by using Tafel extrapolation and chrono-amperometry methods. Experiments were carried in a conventional three electrode cell assembly using Autolab Potentiostat/ Galvanostat, PGSTAT100 (Nova Software). In three electrode cell assembly, pure iron of dimension $1 \mathrm{~cm} \times 1 \mathrm{~cm}$ is taken as working electrode embedded in araldite epoxy, Pt as counter electrode and saturated calomel electrode (SCE) as reference electrode. The cleaning of the working iron electrode was carried out by $1 / 0,2 / 0,3 / 0$ and 4/0 grade emery papers. The electrodes were then thoroughly cleaned with acetone and trichloroethylene to remove any impurities on the surface.

\subsection{Tafel extrapolation method}

Tafel extrapolation method involves the measurement of over potentials for various current densities. Figure 1 shows a potential vs. log absolute current plot for an applied potential scan. The linear Tafel segments to the anodic and cathodic curves $(-0.2$ to $+0.2 \mathrm{~V}$ versus corrosion potential) were extrapolated to corrosion potential to obtain the corrosion current densities. The slope gives the Tafel slopes $\left(b_{a}\right.$ and $\left.b_{c}\right)$ and the intercept corresponds to $i_{\text {corr }}$ The corrosion current density $\left[i_{\text {corr }}\left(\mathrm{A} / \mathrm{cm}^{2}\right)\right]$ was calculated with the SternGeary equation [58] (Eq.1);

$$
i_{\text {corr }}=\frac{b_{a} \cdot b_{c}}{2.3\left(R_{P}\right)\left(b_{a}+b_{c}\right)}
$$

Corrosion rate (C.R) in mm/year can also be calculated by using following relationship [59] (Eq.2);

$$
\text { C. } R=3.268 \times 10^{3} \frac{i \text { corr }}{\rho} \frac{M W}{z}
$$

where MW is the molecular weight of the specimen $(\mathrm{g} / \mathrm{mole})$, $\mathrm{Q}$ is density of the specimen $\left(\mathrm{g} / \mathrm{m}^{3}\right)$ and $\mathrm{z}$ is the number of electrons transferred in corrosion reactions.

The corrosion protection efficiency (\% P.E.) was determined from the measured $\mathrm{i}_{\text {corr }}$ (corrosion current densities with blank mild steel electrode $\left(\mathrm{i}_{\text {corr }}{ }^{2}\right)$ without coatings and corrosion current densities with a mild steel electrode coated with polymer coated ( $\mathrm{i}_{\text {corr }}^{\mathrm{c}}$ ) values by using the following relationship;

$$
\text { P.E. }(\%)=\frac{i_{\text {corr }}^{0}-i_{\text {corr }}^{c}}{i_{0}} \times 100
$$




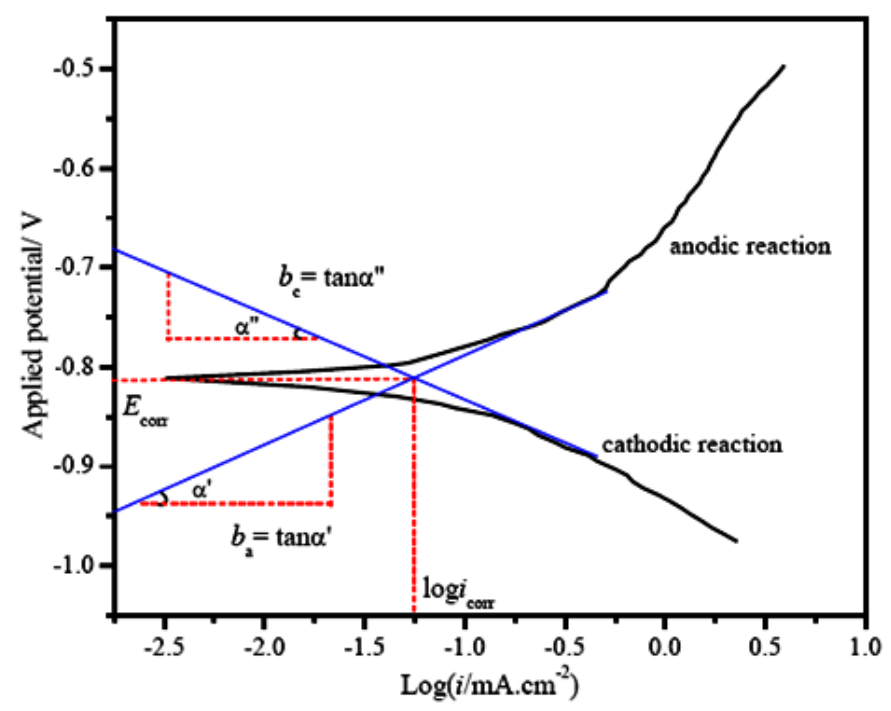

Figure 1. Schematic polarization curve showing Tafel extrapolation.

\subsection{Weight loss method}

The weight loss methods have also been performed for corrosion study. Polymer coated mild steel specimens of dimension $4 \times 3.5 \mathrm{~cm}^{2}$ have been tested for same span of time by immersing the samples in $1.0 \mathrm{M} \mathrm{HCl}$ or aqueous $3.5 \% \mathrm{NaCl}$ solution for 60 days. The uncoated and polymers coated mild steel specimens were weighed in an electronic balance with an accuracy of $0.1 \mathrm{mg}$. before immersion in saline medium. After the 60 days of immersion the mild steel specimens were withdrawn from the tested solution, washed thoroughly with distilled water followed by acetone and dried with air, then weighed again. The performance of the coating was examined visually and through calculation of the weight loss. Weight loss (W.L) is expressed as the loss in the weight per unit area or per unit area per unit time $\left(\mathrm{g} \mathrm{cm}^{-2} \mathrm{~h}^{-1}\right)$ as follows:

$$
W \cdot L=\frac{w_{0}-w_{1}}{a \cdot t}
$$

where, $\mathrm{w}_{0}=$ initial weight of the sample before immersion (g); $\mathrm{w}_{1}=$ weight of the sample after immersion (mg); $a=$ surface area $\left(\mathrm{cm}^{2}\right)$ of specimen; $\mathrm{t}=$ end time $(\mathrm{h})$ of each experiment. If we introduce the density of metal; $\mathrm{d}\left(\mathrm{g} / \mathrm{cm}^{3}\right)$, the loss in the thickness of metal per unit time can be calculated. Corrosion rate (C.R) in $\mathrm{mm} /$ year can also be calculated by weight loss method as follows: 


$$
C . R(\mathrm{~mm} / \text { year })=\frac{\left(w_{0}-w_{1}\right) \times 87.6}{\text { a.t.d }}
$$

\subsection{Surface study}

Surface studies comprise the analysis of surface of metals before and after corrosion in order to estimate the rate as well as mechanism of corrosion. Techniques like scanning electron microscopy and electron probe micro analysis are used to study the structure, chemical composition of corrosion product formed onto metal surface. Other techniques like atomic force microscopy and ellipsometry are used to study the surface of metals with and without corrosion.

\section{Synthesis of the $\mathrm{SiO}_{2}$ nanoparticles}

The syntheses of mono disperse uniform- sized $\mathrm{SiO}_{2}$ nanoparticles were carried out by using ammonia as catalyst and ethanol as solvent. Hydrolysis method of tetra-ethylorthosilicates (TEOS) was used for synthesizing $\mathrm{SiO}_{2}$ nanoparticles. Aqueous ammonia (0.1M) was added to a solution containing ethanol $(1.0 \mathrm{M})$ and $20 \mathrm{ml}$ of deionized water which was stirred for $1 \mathrm{~h}$ then $0.05 \mathrm{M}$ TEOS was added and again stirred for $1 \mathrm{~h}$ at room temperature. Appearance of white turbid suspension indicating the formation of silicon dioxide, this suspension was retrieved by centrifugation and further calcination at $823 \mathrm{~K}$ for 6 hours.

\section{Preparation of $\mathrm{PANI} / \mathrm{SiO}_{2}$ composites:}

\subsection{Chemical oxidative polymerization}

$\mathrm{PANI} / \mathrm{SiO}_{2}$ composites were prepared by in situ chemical oxidative polymerization of aniline using APS as an oxidant. Weight ratio of aniline and $\mathrm{SiO}_{2}$ was taken as 1:1 for preparation of $\mathrm{PANI} / \mathrm{SiO}_{2}$ nanocomposites. Aniline was adsorbed on $\mathrm{SiO}_{2}$ particles and $0.2 \mathrm{M}$ phosphoric acid/0.2 M perfluro octanoic acid (PFOA) was added in this solution. Polymerization was initiated by drop wise addition of ammonium persulphate solution (APS) (0.1 M, $(\mathrm{NH})_{4} \mathrm{~S}_{2} \mathrm{O}_{8}$ in distilled water). The polymerization was carried out at a temperature of $0-3 \mathrm{C}$ for a period of 4-6 h. The synthesized polymer composite was isolated from reaction mixture by filtration and washed with distilled water to remove oxidant and oligomers and followed by drying in the vacuum oven at $60^{\circ} \mathrm{C}$.

\subsection{Electro-chemical polymerization}

The electrochemical polymerization of $0.1 \mathrm{M}$ aniline and aniline in the presence of $\mathrm{SiO}_{2}$ in 0.2 $\mathrm{M} \mathrm{H}_{3} \mathrm{PO}_{4} / 0.2 \mathrm{M}$ PFOA was carried out between -0.20 to $1.5 \mathrm{~V}$ on platinum electrode vs. $\mathrm{Ag} /$ $\mathrm{AgCl}$ reference electrode. The polymer film growth was studied by sweeping the potential between -0.20 to $1.5 \mathrm{~V}$ on Pt electrode at a scan rate of $20 \mathrm{mV} / \mathrm{s}$. Prior to polymerization, the 
solution was deoxygenated by passing argon gas through the reaction solution for $30 \mathrm{~min}$. Peak potential values of the corresponding polymer and $\mathrm{PANI}-\mathrm{SiO}_{2}$ composites were recorded in $0.2 \mathrm{M} \mathrm{H}_{3} \mathrm{PO}_{4} / 0.2 \mathrm{M}$ PFOA medium.

\section{Preparation of $\mathrm{PANI} / \mathrm{SiO}_{2}$ composites coated mild steel}

Mild steel coated with $\mathrm{PANI} / \mathrm{SiO}_{2}$ nanocomposites electrode of dimension $1 \mathrm{~cm} \times 1 \mathrm{~cm}$ were employed to carry out the corrosion studies. Surface treatments were applied on the samples including the cleaning of the electrode was carried out by $1 / 0,2 / 0,3 / 0$ and $4 / 0$ grade emery papers. The electrodes were then thoroughly cleaned with acetone and trichloroethylene to remove any impurities on the surface. The powder polymer was mixed with epoxy formulation in various proportions ranging from $1.0 \%$ to $6.0 \mathrm{wt}$. \%. The polymer-epoxy powder coating was applied to a thickness of $45 \pm 3 \mu \mathrm{m}$ using an electrostatic spray gun. After obtaining uniform coverage of the powder the powder-coated panels were placed in air drying oven for curing at $140^{\circ} \mathrm{C}$ for $20 \mathrm{~min}$. The adhesion of the coating was tested by tape test as per ASTM D3359-02 and found to pass the test.

\section{Characterization of $\mathrm{PANI}-\mathrm{SiO}_{2}$ nanocomposites}

\subsection{Electrochemical behaviour}

Figure 2 shows the electrochemical growth behaviour of aniline and aniline- $\mathrm{SiO}_{2}$ in $0.2 \mathrm{M}$ $\mathrm{H}_{3} \mathrm{PO}_{4}$. The polymer film growth was studied by sweeping the potential between -0.20 and 1.5 $\mathrm{V}$ on Pt electrode at a scan rate of $20 \mathrm{mV} / \mathrm{s}$. Peak potential values of the corresponding PANI and PSC were recorded in $\mathrm{H}_{3} \mathrm{PO}_{4}$ medium. First anodic peak (oxidation peak) corresponds to the oxidation of monomer. During the first reverse sweep, a reduction peak appears which shows that the formation of oligomers and polymer on electrode surface as shown in Figure 2.
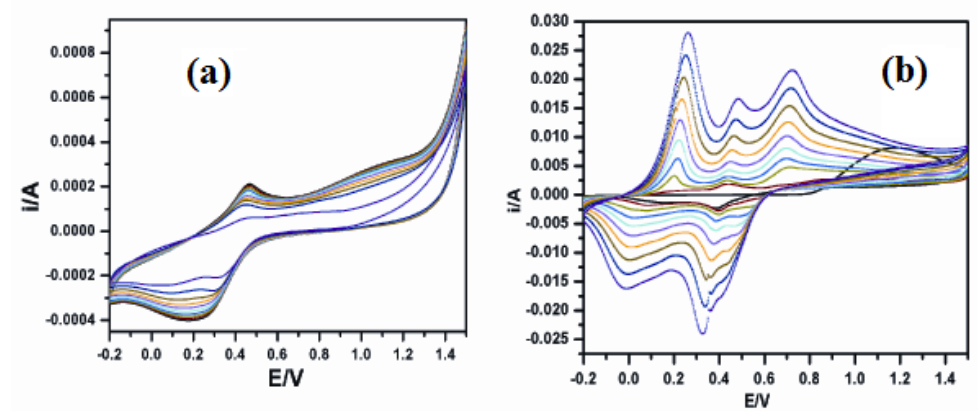

Figure 2. Electrochemical growth behaviour of (a) $0.1 \mathrm{M}$ aniline in $0.2 \mathrm{M} \mathrm{H}_{3} \mathrm{PO}_{4}$ medium and (b) aniline- $\mathrm{SiO}$ in $0.2 \mathrm{M}$ $\mathrm{H}_{3} \mathrm{PO}_{4}$ medium in potential range between $-0.2 \mathrm{~V}$ to $1.5 \mathrm{~V} \mathrm{vs}$. $\mathrm{Ag} / \mathrm{AgCl}$ at scan rate of $20 \mathrm{mV} / \mathrm{s}$. 
After the first scan, well defined oxidation and reduction peaks of polymers between 0.2 and $0.6 \mathrm{~V}$ vs. $\mathrm{Ag} / \mathrm{AgCl}$ appeared. The current values of each oxidation and reduction peaks are greater than that of a previous cycle which indicate the built up of an electro active polymeric material on the electrode surface.

Figure 3 shows the cyclic voltammogram of $\mathrm{PANI}-\mathrm{SiO}_{2}$ composite and the inset figure shows the cyclic voltammogram of PANI in $\mathrm{H}_{3} \mathrm{PO}_{4}$ medium. We have observed quite interesting observation when we recorded the cyclic voltammogram of aniline in phosphoric acid medium and when $\mathrm{SiO}_{2}$ nanoparticles were incorporated in the monomer matrix. On recording the cyclic voltammogram of aniline in $\mathrm{H}_{3} \mathrm{PO}_{4}$ medium, it was observed that anodic peak potential is observed at $0.456 \mathrm{~V}$.

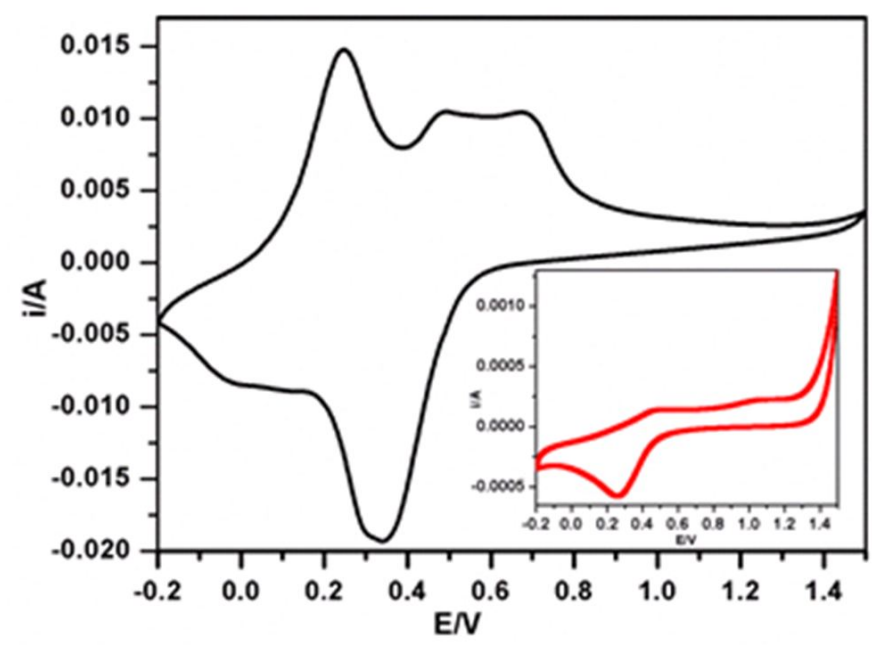

Figure 3. Cyclic voltammogram of PSC and inset shows the cyclic voltammogram of PANI in $\mathrm{H}_{3} \mathrm{PO}_{4}$ medium at a scan rate of $20 \mathrm{mV} / \mathrm{s}$.

However, in the presence of $\mathrm{SiO}_{2}$ matrix, these peaks appeared at $0.247 \mathrm{~V}$. The reason for getting these deviations in $\mathrm{H}_{3} \mathrm{PO}_{4}$ medium is that phosphoric acid is a weak protonic acid whose pKa1 value is 2.21 which results in shifting of peak potential value to $0.456 \mathrm{~V}$. Conventionally, in strong acidic medium like $1.0 \mathrm{M} \mathrm{HCl}$ medium, these values of peak potential for PANI are observed at $0.1 \mathrm{~V}$. However, when the CV was recorded for aniline in the presence of $\mathrm{SiO}_{2}$ and $\mathrm{H}_{3} \mathrm{PO}_{4}$ medium, there is a possibility that protons from phosphoric acid medium might have protonated $\mathrm{SiO}_{2}$ resulting in generation of well-defined peaks as observed in the growth behavior of $\mathrm{CV}$ resulting in observing peak potential values at $0.247 \mathrm{~V}$ (EaI). These experiments were repeated by us number of times and each time this type of cyclic voltammogram was observed which has led us to draw the above conclusion. Protons from phosphoric acid might have led to the formation of protonated silica thereby shifting of peak potential values which might have enhanced the electropolymerization of aniline. 


\subsection{FTIR spectra}

Figure 4 shows the FTIR spectra of $\mathrm{SiO}_{2}$, PANI and PANI-SiO${ }_{2}$. PANI showed the main characteristics bands at 1565 and $1475 \mathrm{~cm}^{-1}$ attributed to the stretching mode of $\mathrm{C}=\mathrm{N}$ and $\mathrm{C}=\mathrm{C}$, the bands at 1292 and $1245 \mathrm{~cm}^{-1}$ indicating the $\mathrm{C}-\mathrm{N}$ stretching mode of benzenoid ring and the band at $1117-1109 \mathrm{~cm}^{-1}$ is assigned to a plane bending vibration of $\mathrm{C}-\mathrm{H}$ mode which is found during protonation [60]. The FTIR spectra of $\mathrm{SiO}_{2}$ indicated that the characteristic peak at $1081 \mathrm{~cm}^{-1}$ and $807 \mathrm{~cm}^{-1}$ are assigned to the stretching and bending vibration of Si-O-Si respectively. By comparing the peaks of PANI and PSC, it was observed that some peaks of PSC were shifted due to the presence of $\mathrm{SiO}_{2}$ particles in polymer matrix. For example, the peaks at $1565 \mathrm{~cm}^{-1}, 1475 \mathrm{~cm}^{-1}, 1292 \mathrm{~cm}^{-1}$, and $1245 \mathrm{~cm}^{-1}$ shifted to higher wavenumbers, and the bending vibration of Si-O-Si peak at $1056 \mathrm{~cm}^{-1}$ shifted to the lower wavenumbers. These changes also indicate that an interaction exists between PANI molecule and $\mathrm{SiO}_{2}$ particles. These peaks were also observed in PSC indicating the interaction of $\mathrm{SiO}_{2}$ particles in polyaniline chain.

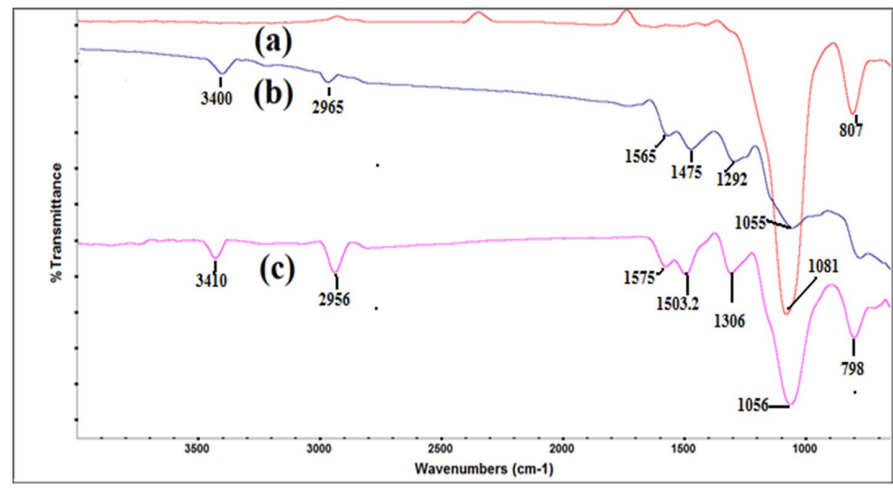

Figure 4. FTIR spectra of (a) $\mathrm{SiO}_{2}$ (b) PANI and PSC.

\subsection{Thermogravimetric analysis}

Figure 5 shows the thermo-gravimetric curves (TG) of pure $\mathrm{SiO}_{2}, \mathrm{PANI}$ and their composites. The materials were heated from 25 to $800^{\circ} \mathrm{C}$ under a constant heating rate of $10^{\circ} \mathrm{C} / \mathrm{min}$ and in the inert atmosphere of nitrogen gas $(60 \mathrm{ml} / \mathrm{min})$. The $\mathrm{SiO}_{2}$ particle has excellent thermal stability up to $800^{\circ} \mathrm{C}$ and weight loss was only $0.15 \%$. The TGA curve of PSC indicated, first weight loss at $110^{\circ} \mathrm{C}$ may be attributed to the loss of water and other volatiles species. The weight loss in the second step at about $280^{\circ} \mathrm{C}$ involves the loss of phosphate ions as well as onset of degradation of polyaniline backbone. The increasing $\mathrm{SiO}_{2}$ content slightly affects the decomposition temperature (DT) which increases from $280^{\circ} \mathrm{C}$ (PANI) to $295^{\circ} \mathrm{C}$ (PSC). The third weight loss step between 300 to $550^{\circ} \mathrm{C}$ can be ascribed to the complete degradation of dopant as well as polymeric backbone. The composites show little weight loss between the $500-800^{\circ} \mathrm{C}$ and the residue remaining in this region gives an approximate estimate of filler content. Therefore, the final weight of $\mathrm{SiO}_{2}$ incorporated in polymer was found to $21 \%$. The 
results indicate that actually incorporated $\mathrm{SiO}_{2}$ fraction is less than the ratio of aniline: $\mathrm{SiO}_{2}$ taken in the initial reaction mass.

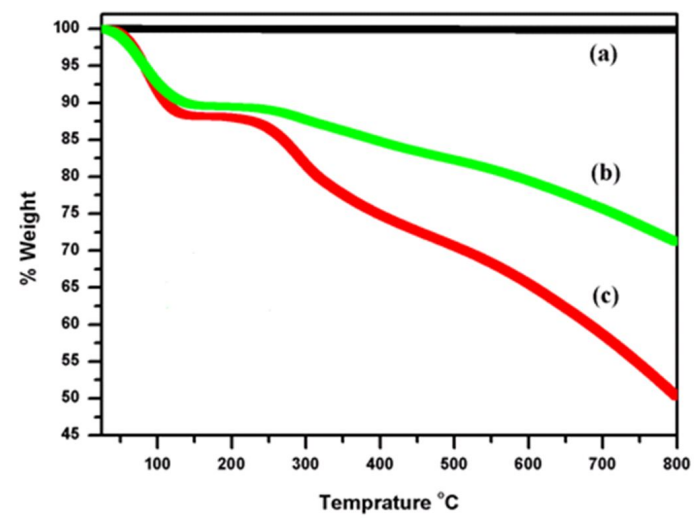

Figure 5. Thermal gravimetric analysis of $\mathrm{SiO}_{2}, \mathrm{PANI}$ and (c) PSC doped with $\mathrm{H}_{3} \mathrm{PO}_{4}$.

The TGA data clarify that these composites are thermally stability up to $295^{\circ} \mathrm{C}$, which envisages them as a good candidate for melt blending with conventional thermoplastics like polyethylene, polypropylene, polystyrene etc.

\subsection{UV-Visible spectra}

Figure 6 shows the UV absorption spectra of polyaniline and its composite with $\mathrm{SiO}_{2}$. We have measured the UV absorption spectra of polymer using dimethyl sulfoxide (DMSO) as a solvent from 250 to $1100 \mathrm{~nm}$.

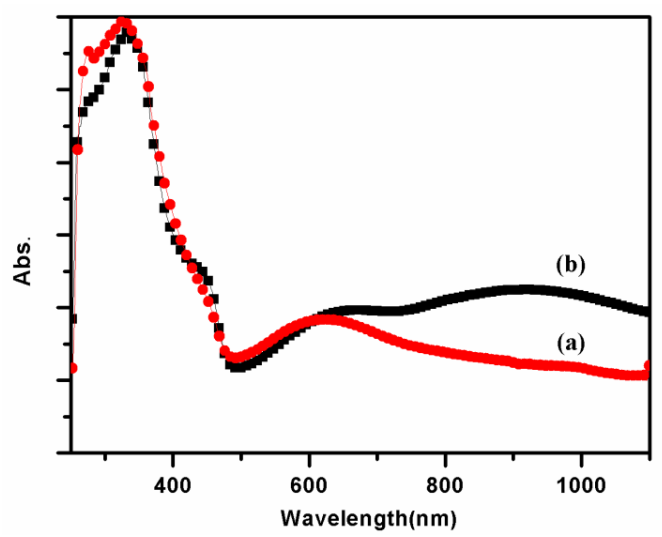

Figure 6. UV-Visible spectra of (a) PANI \& (b) PSC in DMSO. 
The UV-visible absorption data indicates that $\lambda_{\max }$ values in case of polyaniline doped with o-phosphoric acid medium in DMSO solvent lies at 326nm, 431nm and $619 \mathrm{~nm}$ whereas in PSC composite these values lies at $336 \mathrm{~nm}, 447 \mathrm{~nm}$ and $654 \mathrm{~nm}$. In case of polyaniline, $\pi-\pi^{*}$ transition [61, 62] occurs at $326 \mathrm{~nm}$ whereas in case of PSC composite, this transition value lies at $336 \mathrm{~nm}$. This indicates that the addition of $\mathrm{SiO}_{2}$ particles absorbed in aniline matrix and on polymerization in o-phosphoric acid medium may have caused some interactions with polymer matrix resulting in shifting of bands from $326 \mathrm{~nm}$ to 336 $\mathrm{nm}$. This is the reason of shifting of polaronic bands which also shows a shift from 431 $\mathrm{nm}$ to $447 \mathrm{~nm}$ and $619 \mathrm{~nm}$ to $654 \mathrm{~nm}$.

\section{Anticorrosive properties of PANI and PSC coated mild steel in $1.0 \mathrm{M}$ $\mathrm{HCl}$ medium.}

\subsection{Chronoamperometry method}

Figure 7 shows the chronoamperometric response of uncoated, epoxy coated, PANI and PSC coated mild steel sample in $1.0 \mathrm{M} \mathrm{HCl}$. After the samples reached a stable OCP (open circuit potential), a potential in the range of $1.2 \mathrm{~V}$ vs SCE was applied and current was recorded as a function of time. It was observed that the current of PANI and PSC coated mild steel sample remained at a very small value as compared with the uncoated mild steel electrode indicating the good protective properties by these polymers coating. Moreover, it has been observed that the current density value of PSC coated mild steel was lower than that of PANI-coated mild steel sample. The decrease in current density with increasing amount of PSC material in epoxy resin. Hence, chronoamperometric test results showed that mild steel coated with $\mathrm{PANI} / \mathrm{SiO}_{2}$ composites shows the higher corrosion protection performance as compared to PANI coated mild steel samples. This statement was further confirmed by other corrosion test methods like Tafel extrapolation and weight loss methods.

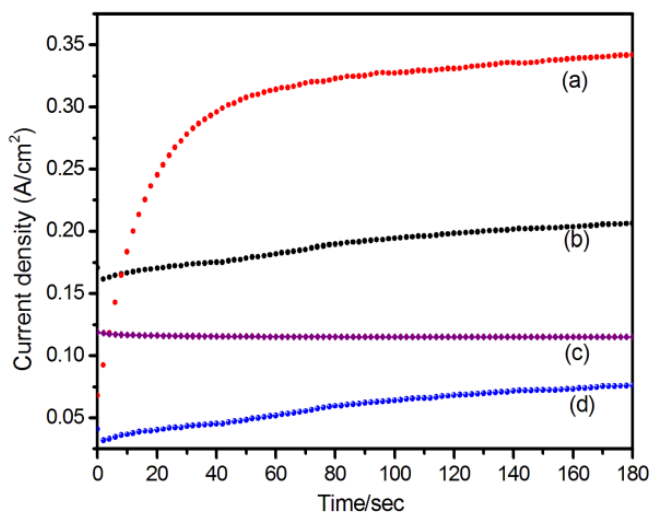

Figure 7. Chronoamperometric response of (a) uncoated (b) epoxy coated (c) PANI and (d) PSC coated mild steel sample in $1.0 \mathrm{M} \mathrm{HCl}$. 


\subsection{Tafel extrapolation method}

Tafel polarization behaviour of mild steel in $1.0 \mathrm{M} \mathrm{HCl}$ with uncoated, epoxy coated, PANI and PSC coated mild steel are shown in the Figure 8\& Figure 9.

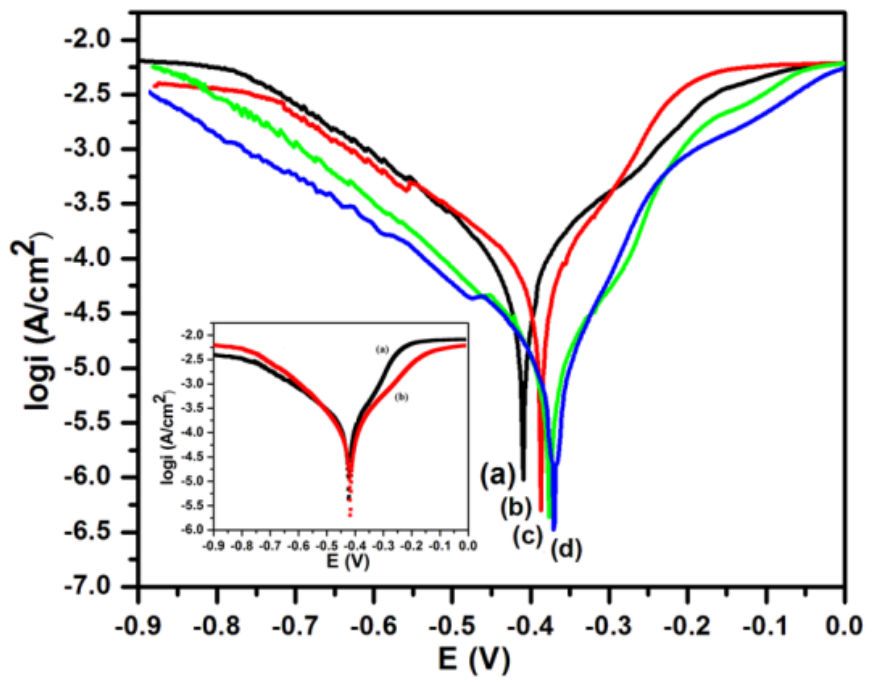

Figure 8. Tafel curves of PANI coated mild steel electrode with different loading level of PANI in epoxy resin (a) $1.5 \%$ (b) $3.0 \%$ (c) $4.5 \%$ (d) $6.0 \%$ whereas the inset shows (a) blank mild steel electrode and (b) epoxy coated mild steel electrode in $1.0 \mathrm{M} \mathrm{HCl}$.

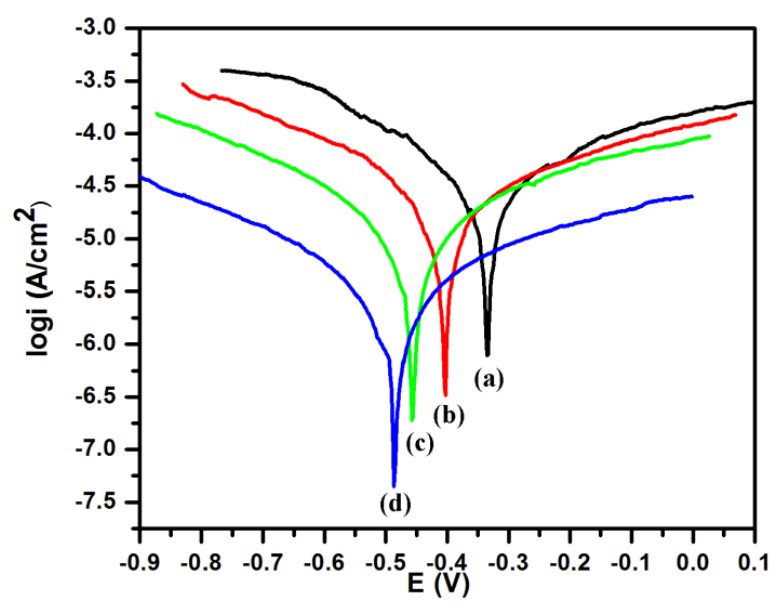

Figure 9. Tafel curves of PSC coated mild steel electrode with different loading level of PSC in epoxy resin (a) $1.5 \%$ (b) $3 \%$ (c) $4.5 \%$ (d) $6.0 \%$. 
The corrosion kinetic parameters derived from these curves are given in the Table 1. As shown in Table 1, PSC coated mild steel sample showed a remarkable current shift from 132 $\mu \mathrm{A}$ to $0.09 \mu \mathrm{A}$ versus $\mathrm{Ag} / \mathrm{AgCl}$ in the corrosion current $\left(\mathrm{i}_{\text {corr }}\right)$, relative to the value of the uncoated mild steel.

The significant reduction in the corrosion current density $\left(\mathrm{i}_{\text {corr }}\right)$ in polymer coated mild steel indicated the effective corrosion protection performance of these polymers. The corrosion current values $\left(i_{\text {corr }}\right)$ were found to be decreased from $132 \mu \mathrm{A} / \mathrm{cm}^{2}$ for uncoated mild steel sample to $107.6 \mu \mathrm{A} / \mathrm{cm}^{2}$ for epoxy coated mild steel sample to $0.09 \mu \mathrm{A} / \mathrm{cm}^{2}$ for PSC coated mild steel samples.

The corrosion current values $\left(\mathrm{i}_{\text {corr }}\right)$ decreased with increasing the concentration of PSC in epoxy resin. $\mathrm{i}_{\text {corr }}$ value decreased from $15.4 \mu \mathrm{A} / \mathrm{cm}^{2}$ at $1.5 \mathrm{wt}$. $\%$ to $0.09 \mu \mathrm{A} / \mathrm{cm}^{2}$ at $6.0 \mathrm{wt}$ \% loading of conducting material in epoxy resin as shown in Figure 9. While PANI coated mild steel showed the $i_{\text {corr }}$ in the range of $10.9 \mu \mathrm{A} / \mathrm{cm}^{2}$ at $6.0 \%$ loading as shown in Figure 8 .

\begin{tabular}{ccccc}
\hline Sample name & $\begin{array}{c}\text { Loading level } \\
\text { of polymer } \\
(\%)\end{array}$ & $\mathrm{I}_{\text {corr }}\left(\mu \mathrm{A} / \mathbf{c m}^{2}\right)$ & $\begin{array}{c}\text { Corrosion rate } \\
(\mathbf{m m} / \text { year) }\end{array}$ & $\begin{array}{c}\text { Protection } \\
\text { efficiency } \\
\mathbf{( \% )}\end{array}$ \\
\hline Blank mild steel & - & 132.0 & 1.54 & -- \\
\hline Epoxy coated mild steel & -- & 107.6 & 1.26 & 18.48 \\
\hline PANI & 1.5 & 98.8 & 1.15 & 25.15 \\
\cline { 2 - 5 } & 3.0 & 75.4 & 0.88 & 42.88 \\
\cline { 2 - 5 } & 4.5 & 20.5 & 0.23 & 84.47 \\
\hline PANI-SiO 2 & 6 & 10.9 & 0.13 & 91.74 \\
\hline Composite (PSC) & 1.5 & 15.4 & 0.18 & 88.33 \\
\cline { 2 - 5 } & 3.0 & 9.09 & 0.11 & 93.11 \\
\hline & 4.5 & 5.12 & 0.05 & 96.12 \\
\hline & 6 & 0.09 & 0.0011 & 99.93 \\
\hline
\end{tabular}

Table 1. Tafel parameters for corrosion of mild steel in $1.0 \mathrm{M} \mathrm{HCl}$ with different loading level of PANI \& PSC in epoxy resin.

The corrosion protection efficiency calculated from Tafel parameter revealed that PANI coated mild steel showed $25 \%$ protection efficiency at $1.5 \mathrm{wt} . \%$ loading while PSC coated mild steel showed $88 \%$ P.E at the same loading level. Up to $99.93 \%$ protection efficiency have been achieved by using $6.0 \mathrm{wt}$.\% loading of PSC in epoxy resin.

\subsection{SEM studies of uncoated and coated mild steel observed by weight loss method}

The scanning electron micrographs of $\mathrm{SiO}_{2}$ particles, PANI and PSC are shown in Figure 10. $\mathrm{SiO}_{2}$ particles showed spherical shaped morphology and PANI showed globular morphology. Figure $10 \mathrm{~b}$ shows the TEM image of of $\mathrm{SiO}_{2}$ particles, which indicates the dimension of 
$\mathrm{SiO}_{2}$ particles, was found to be $90-100 \mathrm{~nm}$. Morphology of PSC indicates the incorporation of $\mathrm{SiO}_{2}$ particles in PANI matrix. SEM image of PSC revealed that the entrapment of $\mathrm{SiO}_{2}$ particles in the globular space of PANI matrix during in situ polymerisation of polyaniline.
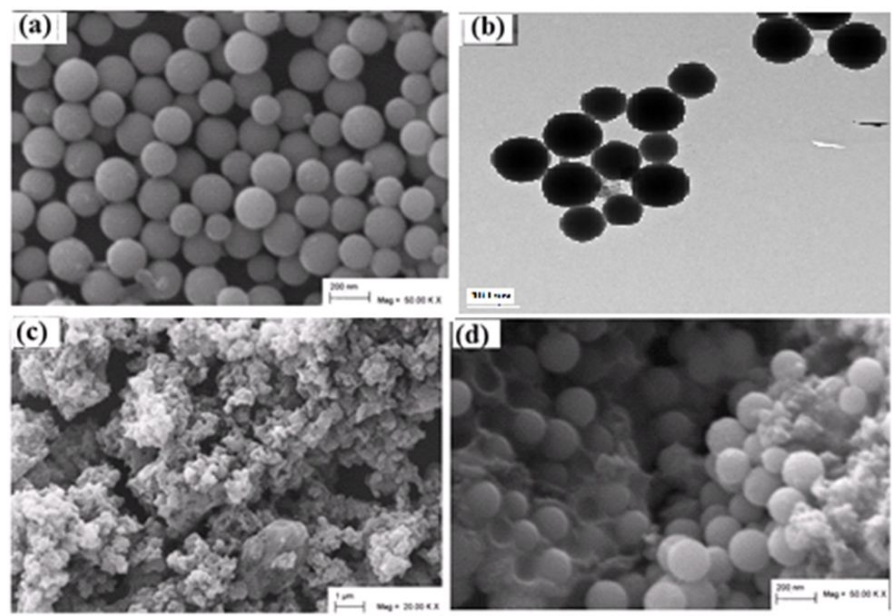

Figure 10. SEM micrographs powder sample of (a) $\mathrm{SiO}_{2}$ (c) PANI (d) PSC and ( b) TEM image of $\mathrm{SiO}_{2}$ particles.
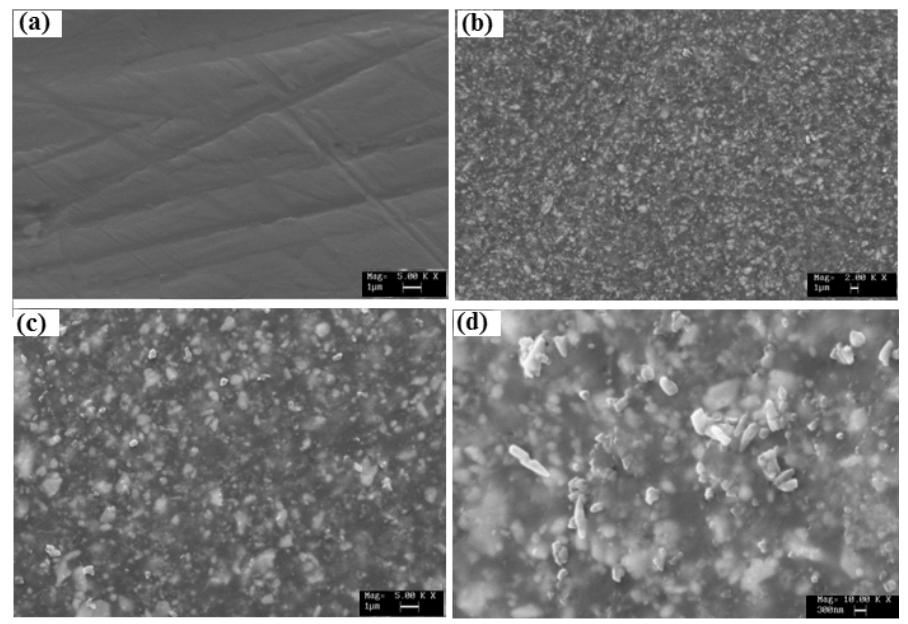

Figure 11. SEM micrographs of (a) blank mild steel electrode (b) blank epoxy resin coated electrode (c) PANI coated (d) PSC coated electrode before immersion in $1.0 \mathrm{M} \mathrm{HCl}$.

SEM images of uncoated, epoxy coated and polymer coated samples before and after the immersion test of 60 days have been shown in Figure 11 \& Figure 12. These images clearly show 
the formation of large pits on the surface of mild steel after immersion. These pits and cracks were developed during the corrosion of mild steel in acidic medium. In the case PANI coated sample, few pits still appeared on mild steel surface. While, PSC coated mild steel samples did not show any cracks and pits on the metal surface. No detachment of coating from mild steel substrate was also observed after the immersion of these samples in $1.0 \mathrm{M} \mathrm{HCl}$ medium for 60 days of immersion indicating strong adherence of PSC composite to the mild steel substrate and it is resistant to corrosion in aqueous $1.0 \mathrm{M} \mathrm{HCl}$ solution as shown in Figure 13.

When epoxy coated mild steel sample was immersed in the acidic medium for 60 days, detachment of coating from mild steel substrate have been observed. The pits were also appeared on the metal surface as shown in Figure $12 \mathrm{~b}$.
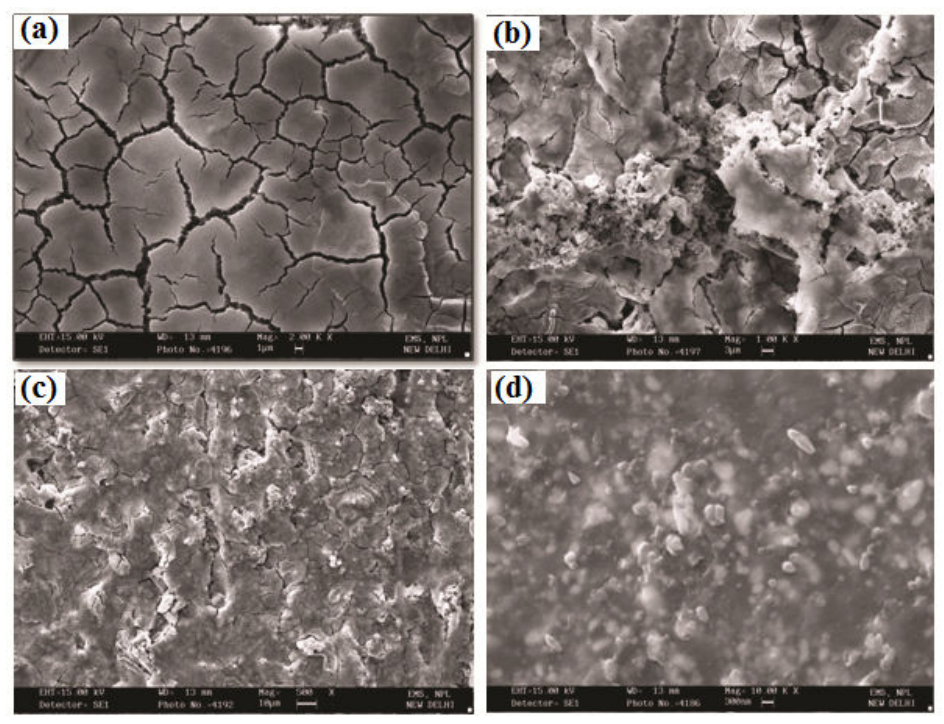

Figure 12. SEM micrographs of (a) blank mild steel electrode (b) blank epoxy resin coated electrode (c) PANI coated (d) PSC coated electrode after immersion in $1.0 \mathrm{M} \mathrm{HCl}$ for 60 days.

It was found that the PSC content has a great influence on the anticorrosive performance of the coating. The corrosion protection effect of PSC coated mild steel sample improved slowly when PSC content in epoxy formulation increases from 1.5 to $3.0 \mathrm{wt}$. \% Afterward, an excellent corrosion protection effect appears at $6.0 \mathrm{wt}$ \% loading of PSC content in epoxy resin.

Corrosion rates (C.R) in mm/year have also been calculated by weight loss method and the values have been given in Table 2. It was observed that the corrosion rate was highest for uncoated mild steel in $\mathrm{HCl}$ medium. After 60 days of immersion, the C.R value of uncoated mild steel was found to $7.25 \mathrm{~mm} /$ year. Epoxy and PANI coated samples showed C.R. value of $6.37 \mathrm{~mm} /$ year and $1.90 \mathrm{~mm} /$ year respectively. While in the case of PSC coated sample in $6.0 \%$ loading, C.R. value reduced to $0.73 \mathrm{~mm} /$ year. 


\begin{tabular}{|c|c|c|c|c|c|c|c|}
\hline $\begin{array}{c}\text { Sample } \\
\text { name }\end{array}$ & $\begin{array}{l}\text { Loading } \\
\text { level of } \\
\text { polymer } \\
\text { (\%) }\end{array}$ & $\begin{array}{c}\text { Initial } \\
\text { Weight } \\
\text { (mg) }\end{array}$ & $\begin{array}{l}\text { Weight After } \\
\text { immersion in } \\
\mathrm{HCl} \text { for } 60 \\
\text { days (mg) }\end{array}$ & $\begin{array}{l}\text { Weight loss } \\
\text { (mg) }\end{array}$ & $\begin{array}{l}\text { Weight } \\
\text { loss (\%) }\end{array}$ & $\begin{array}{c}\text { C.R }(\mathrm{mm} / \\
\text { year) }\end{array}$ & $\begin{array}{c}\text { Protection } \\
\text { Efficiency } \\
\text { (\%) }\end{array}$ \\
\hline $\begin{array}{l}\text { Blank mild } \\
\text { steel }\end{array}$ & - & 30354.6 & 17256.30 & 13098.30 & 43.15 & 7.25 & - \\
\hline Blank epoxy & 0 & 31113.4 & 19598.61 & 11514.79 & 37.00 & 6.37 & 12.10 \\
\hline \multirow[t]{4}{*}{ PANI } & 1.5 & 31717.2 & 21518.09 & 10199.11 & 32.15 & 5.64 & 22.13 \\
\hline & 3.0 & 31601.2 & 23698.65 & 7902.55 & 25.00 & 4.37 & 39.67 \\
\hline & 4.5 & 31289.1 & 27021.37 & 4267.73 & 13.63 & 2.36 & 67.42 \\
\hline & 6 & 30454.0 & 27018.20 & 3435.80 & 11.28 & 1.90 & 73.77 \\
\hline \multirow{4}{*}{$\begin{array}{l}\text { PANI-SiO2 } \\
\text { Composite }\end{array}$} & 1.5 & 32487.2 & 29606.00 & 881.20 & 8.86 & 1.59 & 78.00 \\
\hline & 3.0 & 32891.5 & 30397.90 & 2493.60 & 7.58 & 1.38 & 80.96 \\
\hline & 4.5 & 31856.7 & 30031.30 & 1825.40 & 5.73 & 1.01 & 86.06 \\
\hline & 6 & 31773.7 & 30454.20 & 1319.50 & 4.15 & 0.73 & 89.93 \\
\hline
\end{tabular}

Table 2. Weight loss parameter of uncoated and coated mild steel samples after immersion test in $1.0 \mathrm{M} \mathrm{HCl}$ for 60 days.

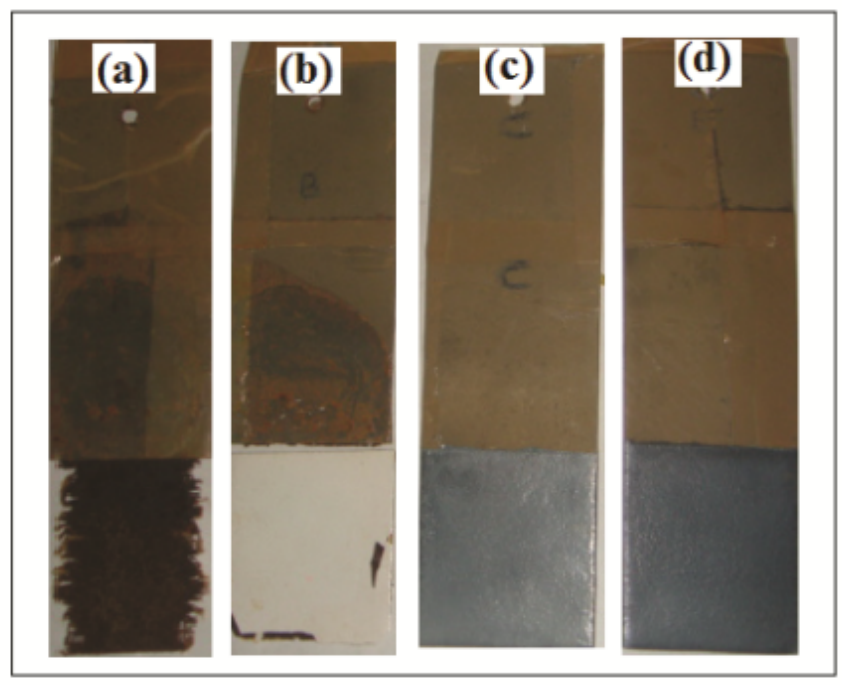

Figure 13. Photographs of (a) blank mild steel electrode (b) blank epoxy resin coated electrode (c) PANI coated (d) PSC coated electrode after immersion in $1.0 \mathrm{M} \mathrm{HCl}$ for 60 days. 


\section{Characterization of hydrophobic PANI $-\mathrm{SiO}_{2}$ Nanocomposites (HPSC)}

\subsection{Electrochemical behaviour}

Figure 14 shows the electrochemical growth behavior of aniline and aniline- $\mathrm{SiO}_{2}$ in $0.2 \mathrm{M}$ PFOA solution. Electrochemical polymeriztion was carried out at $0.9 \mathrm{~V}$ on platinum electrode vs $\mathrm{Ag} / \mathrm{AgCl}$ reference electrode. The polymer film growth was studied by sweeping the potential between -0.20 and $0.9 \mathrm{~V}$ on Pt electrode at a scan rate of $20 \mathrm{mV} / \mathrm{s}$.
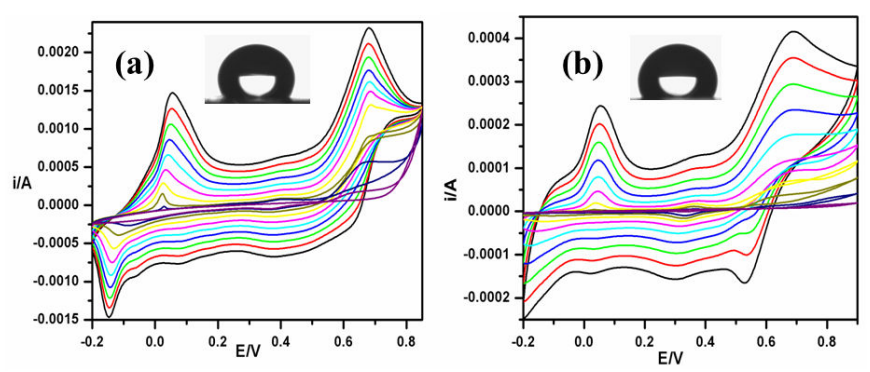

Figure 14. Electrochemical growth behaviour of (a) $0.1 \mathrm{M}$ aniline in $0.2 \mathrm{M} \mathrm{PFOA}$ medium and (b) aniline- $\mathrm{SiO}_{2}$ in $0.2 \mathrm{M}$ PFOA medium in potential range between $-0.2 \mathrm{~V}$ to $0.9 \mathrm{~V}$ vs. $\mathrm{Ag} / \mathrm{AgCl}$ at scan rate of $20 \mathrm{mV} / \mathrm{s}$.

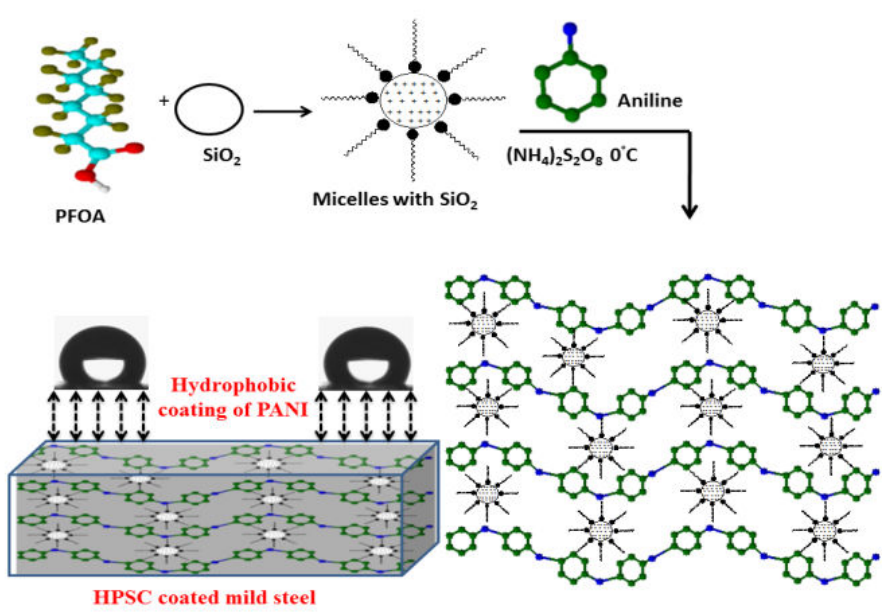

Figure 15. Schematic representation of formation of HPSC coating onto mild steel surface.

Peak potential values of the corresponding PANI and HPSC were recorded in PFOA medium. First anodic peak (oxidation peak) corresponds to the oxidation of monomer. The intensity of this peak gradually decreases with subsequent scans. During the first reverse 
sweep, a reduction peak appears which shows that the formation of oligomers and polymer on electrode surface as shown in Figure 14. Figure 15 shows the Schematic representation of formation of HPSC coating onto mild steel surface. After the first scan, well defined oxidation and reduction peaks of polymers between 0.2 and $0.6 \mathrm{~V}$ vs. $\mathrm{Ag} / \mathrm{AgCl}$ appeared. The current values of each oxidation and reduction peaks are greater than that of a previous cycle which indicate the built up of an electroactive polymeric material on the electrode surface. Moreover, it was observed that current value of PANI film was found to be higher than that of HPSC film which revealed higher conductivity of PANI as compare to HPSC coating on electrode surface.

Cyclic voltammogram of HPSC and PANI in PFOA medium indicates that the first peak potential value of PANI in PFOA medium lies at $0.15 \mathrm{~V}$. Incorporation of $\mathrm{SiO}_{2}$ particle in PANI, the first peak potential value shifted from $0.15 \mathrm{~V}$ to $0.041 \mathrm{~V}$ vs $\mathrm{Ag} / \mathrm{AgCl}$ as shown in Figure 16.

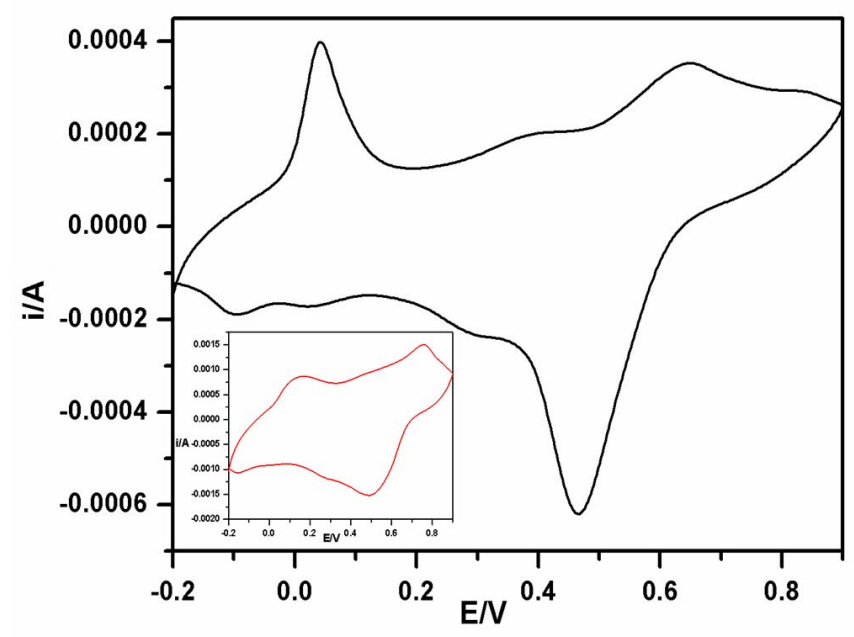

Figure 16. Cyclic voltammogram of HPSC and inset figure shows the cyclic voltammogram of PANI in PFOA medium at a scan rate of $20 \mathrm{mV} / \mathrm{s}$.

This implies that the polymerization of aniline leads to larger peak potential shift as compared to the aniline in presence of $\mathrm{SiO}_{2}$ which indicates the presence of $\mathrm{SiO}_{2}$ particles in the polymer chain induce some change in configurations along the polymer backbone which is responsible for the negative shift in the oxidation potential.

\subsection{FTIR spectra}

The Figure 17 shows the FTIR spectra of $\mathrm{SiO}_{2}$, PANI and HPSC. PANI showed the main characteristics bands at 1554 and $1438-1440 \mathrm{~cm}^{-1}$ attributed to the stretching mode of $\mathrm{C}=\mathrm{N}$ and $\mathrm{C}=\mathrm{C}$, the bands at $1250 \mathrm{~cm}^{-1}$ indicating the $\mathrm{C}-\mathrm{N}$ stretching mode of benzenoid ring.

The FTIR spectra of $\mathrm{SiO}_{2}$ indicated that the characteristic peak at $1081 \mathrm{~cm}^{-1}$ and $807 \mathrm{~cm}^{-1}$ are assigned to the stretching and bending vibration of $\mathrm{Si}-\mathrm{O}-\mathrm{Si}$ respectively. These peaks were 
also observed in HPSC indicating the interaction of $\mathrm{SiO}_{2}$ particles in polyaniline chain. HPSC and PANI showed a characteristic strong peak at $1738 \mathrm{~cm}^{-1}$ due to $\mathrm{C}=\mathrm{O}$ stretching mode and peak at $1365 \mathrm{~cm}^{-1}$ due to C-F stretching mode [61], which indicates the interaction of PFOA dopant in the polymer chain.

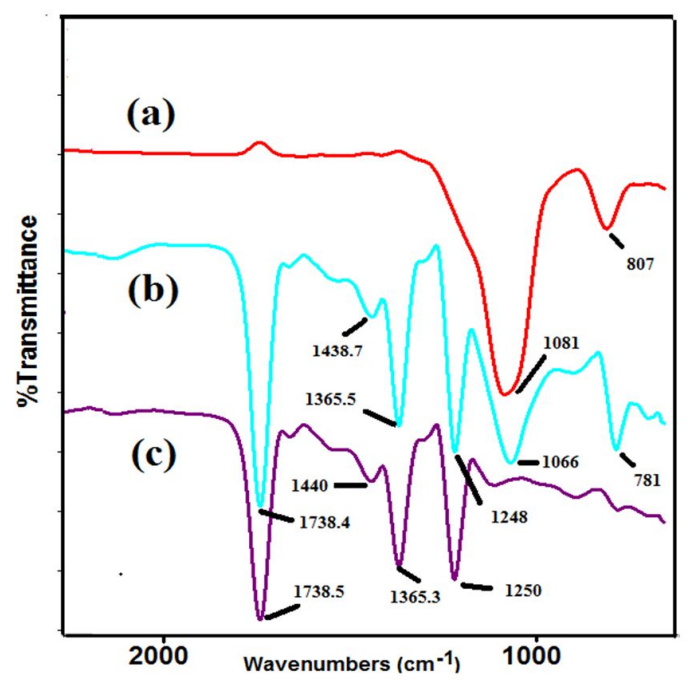

Figure 17. FTIR spectra of (a) $\mathrm{SiO}_{2}$ (b) PANI and (c) HPSC.

\subsection{Wettability of HPSC coating}

The surface wettability was measured by static contact angle measurements with water $(\gamma=72.8 \mathrm{mN} / \mathrm{m})$ to determine surface hydrophobicity. The drop volume used for the measurements was $2.0 \mu \mathrm{L}$. The PANI-SiO${ }_{2}$ nanocomposite (HPSC) coated electrodes exhibited hydrophobic properties with static water contact angle of about $115^{\circ}$ as shown in Figure 14 .

\section{Anticorrosive properties of HPSC coated mild steel in $3.5 \% \mathrm{NaCl}$ solution}

\subsection{Tafel Extrapoaltion method}

Tafel polarization behaviour of mild steel in $3.5 \% \mathrm{NaCl}$ solution with uncoated, epoxy coated, PANI and HPSC coated mild steel are shown in the Figure 18\& Figure 19. The corrosion kinetic parameters derived from these curves are given in the Table 3. As shown in Table 3. HPSC coated mild steel sample showed a remarkable current density shift from 106.5 
$\mu \mathrm{A} / \mathrm{cm}^{2}$ to $4.36 \mu \mathrm{A} / \mathrm{cm}^{2}$ versus $\mathrm{Ag} / \mathrm{AgCl}$ in the corrosion current $\left(\mathrm{I}_{\text {corr }}\right)$, relative to the value of the uncoated mild steel.

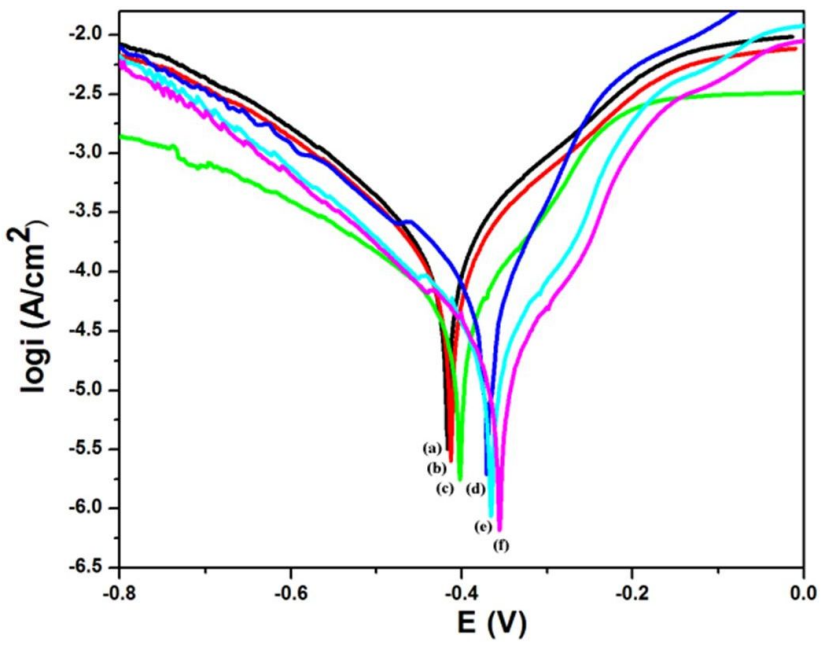

Figure 18. Tafel curves of uncoated and polymer coated mild steel electrode in $3.5 \% \mathrm{NaCl}$ solution (a) blank electrode (b) epoxy coated mild steel (c) PANI coated mild steel at 1.5 wt. \% loading (d) 3.0 wt. \% loading (e) 4.5 wt.\% loading and (f) 6.0 wt. \% loading of PANI in epoxy resin.

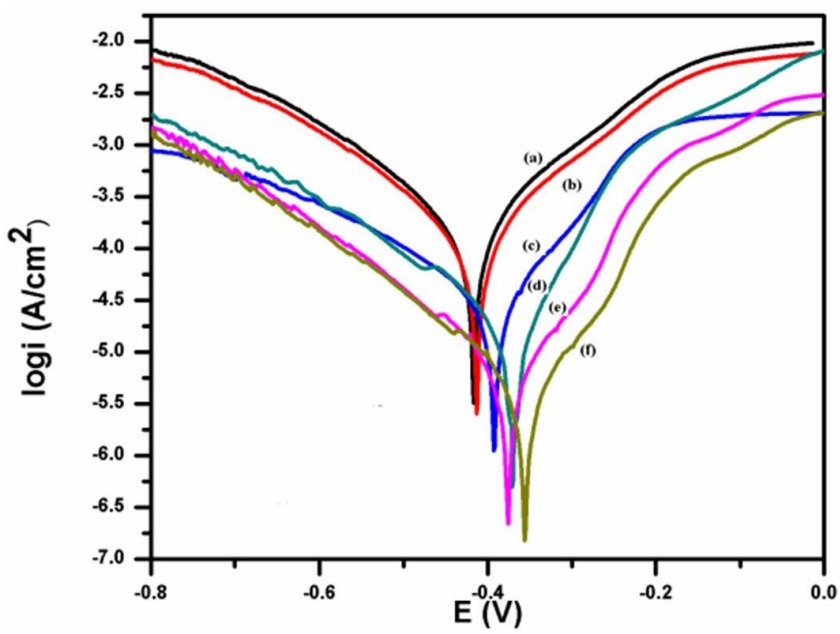

Figure 19. Tafel curves of (a) blank mild steel (b) epoxy coated mild steel (c) HPSC coated mild steel at 1.5 wt. \% loading (d) 3.0 wt. \% loading (e) 4.5 wt.\% loading (f) 6.0 wt. \% in $3.5 \% \mathrm{NaCl}$ solution.

The significant reduction in the corrosion current density $\left(\mathrm{i}_{\text {corr }}\right)$ in polymer coated mild steel indicated the effective corrosion protection performance of these polymers. The corrosion 
current values $\left(\mathrm{i}_{\text {corr }}\right.$ ) found to be decreased from $106.5 \mu \mathrm{A} / \mathrm{cm}^{2}$ for uncoated mild steel sample to $98 \mu \mathrm{A} / \mathrm{cm}^{2}$ for epoxy coated mild steel sample to $4.36 \mu \mathrm{A} / \mathrm{cm}^{2}$ for HPSC coated mild steel samples. The corrosion current values $\left(\mathrm{i}_{\text {corr }}\right)$ decreased with increasing the concentration of HPSC in epoxy resin. $\mathrm{i}_{\text {corr }}$ value decreased from $32.6 \mu \mathrm{A} / \mathrm{cm}^{2}$ at 1.5 wt. $\%$ to 4.36 $\mu \mathrm{A} / \mathrm{cm}^{2}$ at 6.0 wt. \% loading of conducting material in epoxy resin.

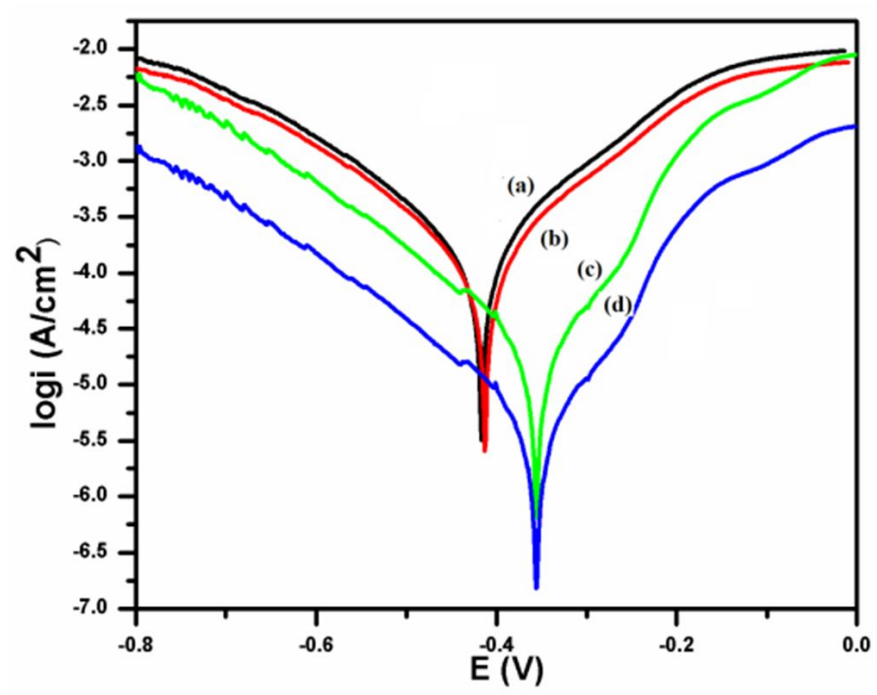

Figure 20. Tafel curves of (a) blank electrode (b) epoxy coated (c) PANI coated mild steel at 6.0 wt. \% loading and (d) HPSC coated mild steel at 6.0 wt. \% loading in $3.5 \% \mathrm{NaCl}$ solution.

\begin{tabular}{|c|c|c|c|c|}
\hline Sample name & $\begin{array}{l}\text { Loading level of } \\
\text { polymer (\%) }\end{array}$ & $\mathrm{I}_{\text {corr }}\left(\mu \mathrm{A} / \mathrm{cm}^{2}\right)$ & $\begin{array}{l}\text { Corrosion rate } \\
\text { (mm/year) }\end{array}$ & $\begin{array}{l}\text { Protection } \\
\text { efficiency (\%) }\end{array}$ \\
\hline Blank mild steel & - & 106.5 & 1.51 & 0 \\
\hline Epoxy coated mild steel & 0 & 98.0 & 1.39 & 7.9 \\
\hline \multirow[t]{4}{*}{ PANI } & 1.5 & 64.5 & 0.91 & 39.43 \\
\hline & 3.0 & 61.6 & 0.87 & 42.16 \\
\hline & 4.5 & 30.2 & 0.42 & 71.6 \\
\hline & 6 & 20.4 & 0.28 & 80.84 \\
\hline \multirow[t]{4}{*}{ HPSC } & 1.5 & 32.6 & 0.45 & 69.39 \\
\hline & 3.0 & 12.8 & 0.17 & 87.98 \\
\hline & 4.5 & 6.16 & 0.08 & 94.21 \\
\hline & 6 & 4.36 & 0.06 & 96.0 \\
\hline
\end{tabular}

Table 3. Tafel parameters for corrosion of mild steel in $3.5 \% \mathrm{NaCl}$ with different loading level of PANI \& HPSC in epoxy resin. 
While PANI coated mild steel showed the $i_{\text {corr }}$ in the range of $20.4 \mu \mathrm{A} / \mathrm{cm}^{2}$ at $6.0 \%$ loading. The corrosion protection efficiency calculated from Tafel parameter revealed that PANI coated mild steel showed the protection efficiency $39.4 \%$ at $1.5 \mathrm{wt} . \%$ loading while HPSC coated mild steel showed $69.4 \%$ P.E at the same loading level.

Up to $96 \%$ protection efficiency have been achieved by using $6.0 \mathrm{wt}$. \% HPSC in epoxy resin. While in case of PANI, only $80.84 \%$ protection has been achieved at $6.0 \mathrm{wt}$. \% loading, as shown in Figure 20.

\subsection{Weight loss method}

Table 4 shows the values of the weight loss from mild steel samples during the immersion test. The results revealed that HPSC coated samples were more protectable to mild steel than that of only PANI coated samples in same immersion time. After the immersion of coated and uncoated samples in $3.5 \% \mathrm{NaCl}$ solution for 60 days, it was observed that uncoated and epoxy coated samples showed the maximum weight loss of $34.18 \%$ and $29.11 \%$ respectively

\begin{tabular}{|c|c|c|c|c|c|c|c|}
\hline $\begin{array}{c}\text { Sample } \\
\text { name }\end{array}$ & $\begin{array}{l}\text { Loading } \\
\text { level of } \\
\text { polymer } \\
(\%)\end{array}$ & $\begin{array}{l}\text { Initial Weight } \\
\text { (before } \\
\text { immersion) } \\
\text { (mg) }\end{array}$ & $\begin{array}{c}\text { Final } \\
\text { Weight } \\
\text { After } \\
\text { immersion } \\
(\mathrm{mg})\end{array}$ & $\begin{array}{l}\text { Weight } \\
\text { loss (mg) }\end{array}$ & $\begin{array}{c}\text { Weight loss } \\
\text { (\%) }\end{array}$ & $\begin{array}{c}\text { C.R }(\mathrm{mm} / \\
\text { year })\end{array}$ & $\begin{array}{l}\text { P.E } \\
\text { (\%) }\end{array}$ \\
\hline $\begin{array}{l}\text { Blank mild } \\
\text { steel }\end{array}$ & - & 32632.1 & 21478.45 & 11153.7 & 34.18 & 4.18 & 0 \\
\hline Blank epoxy & 0 & 30918.7 & 21918.27 & 9000.4 & 29.11 & 3.56 & 14.83 \\
\hline \multirow[t]{4}{*}{ PANI } & 1.5 & 32798.2 & 24913.5 & 7884.7 & 24.04 & 2.94 & 29.67 \\
\hline & 3.0 & 30416.2 & 23502.6 & 6913.6 & 22.73 & 2.78 & 33.49 \\
\hline & 4.5 & 32678.1 & 26642.5 & 6035.6 & 18.47 & 2.26 & 45.93 \\
\hline & 6 & 31567.2 & 28369.4 & 3197.8 & 10.13 & 1.24 & 70.33 \\
\hline \multirow[t]{4}{*}{ HPSC } & 1.5 & 31494.2 & 25541.8 & 5952.4 & 18.9 & 2.32 & 44.50 \\
\hline & 3.0 & 30566.5 & 25935.7 & 4630.8 & 15.15 & 1.86 & 55.50 \\
\hline & 4.5 & 32929.7 & 29926.5 & 3003.2 & 9.12 & 1.12 & 73.20 \\
\hline & 6 & 30804.7 & 30102.4 & 702.3 & 2.28 & 0.28 & 93.30 \\
\hline
\end{tabular}

Table 4. Weight loss parameter of uncoated and coated mild steel samples after immersion test in $3.5 \% \mathrm{NaCl}$ for 60 days.

PANI coated mild steel showed the weight loss up to $10.13 \%$ at 6.0 wt. \% loading while HPSC coated samples at the same loading level showed negligible weight loss (i.e $<3 \%$ ) after 60 days of immersion in $3.5 \% \mathrm{NaCl}$ medium. Corrosion rate (C.R) in mm/year have also been calculated by weight loss method. It was observed that the corrosion rate was highest for uncoated mild steel in $3.5 \% \mathrm{NaCl}$ medium. After 60 days of immersion, the C.R value of uncoated mild steel was found to $4.18 \mathrm{~mm} /$ year. Epoxy and PANI coated samples 
showed C.R. value of $3.56 \mathrm{~mm} /$ year and $1.24 \mathrm{~mm} /$ year respectively. While in the case of HPSC coated sample in $6 \%$ loading, C.R. value reduced to $0.28 \mathrm{~mm} /$ year.

The appearance of the uncoated and HPSC coated mild steel samples after exposure to salt spray fog for 35 days is shown in Figure 21.

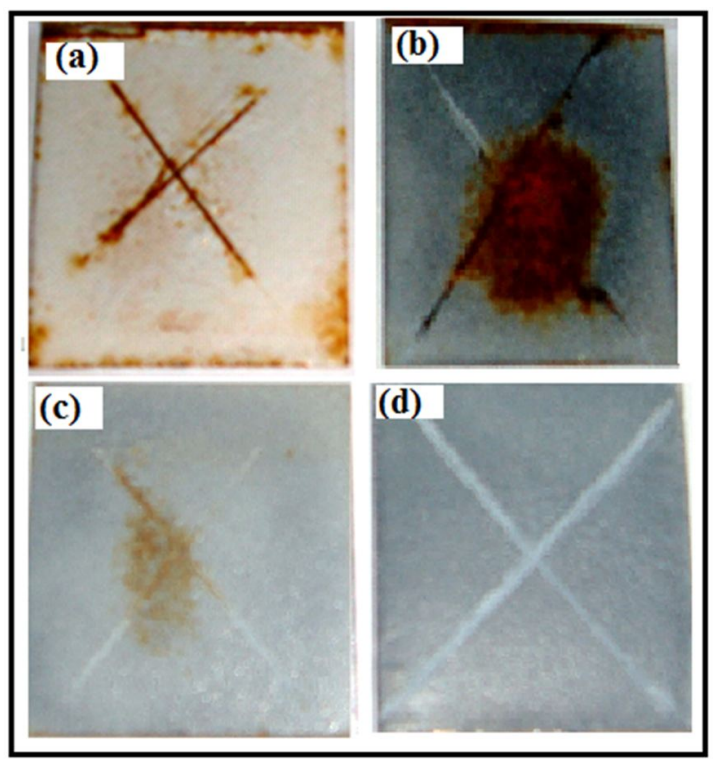

Figure 21. Photograph of (a) epoxy coated (b) PANI (at 6 wt.\% loading) coated (c) HPSC (at 1.5 wt. \% loading) and (d) HPSC (6.0 wt. \% loading mild steel after 35 days of exposure to salt spray test.

It was observed that epoxy coated and PANI coated (at $6.0 \mathrm{wt}$. \% loading) mild steel have more corrosion extended area from the scribes as shown in Figure 21 (a) and 21(b) while HPSC coated mid steel (at $1.0 \mathrm{wt}$. \% loading) showed less corrosion extended area as compared to epoxy and PANI coated mid steel as shown in Figure 21(c). However, HPSC containing coating sample (at $6.0 \mathrm{wt}$.\% loading) were found to be free from rust and blister as shown in Figure 21 (d). Moreover, there was no spreading of rust along the scribed areas.

\subsection{SEM studies of uncoated and coated mild steel before and after immersion test}

It was observed that $\mathrm{SiO}_{2}$ particles showed spherical shaped morphology as shown in Figure 10 a. The scanning electron micrographs of PANI and HPSC are shown in Figure 22. PANI doped with PFOA showed uniform net like morphology as shown in Figure 22(a). Morphology of HPSC was entirely different with incorporation of $\mathrm{SiO}_{2}$ particles in PANI matrix during polymerisation. SEM image of HPSC revealed that the entrapment of $\mathrm{SiO}_{2}$ particles in the globular space of PANI matrix during in-situ polymerisation of polyaniline as shown in Figure 22 (b). 

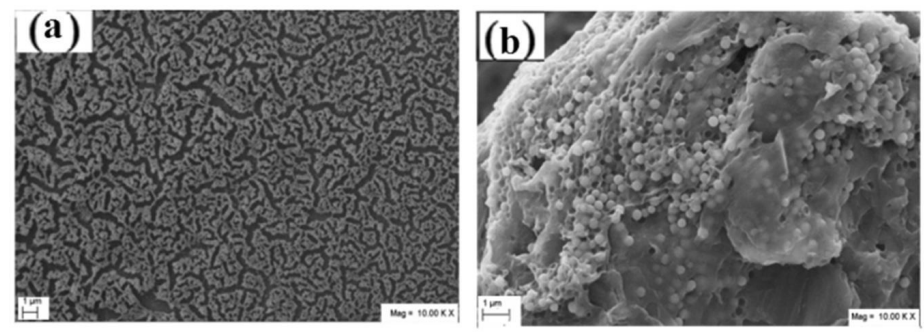

Figure 22. SEM micrographs of powder sample of (a) PFOA doped PANI, and (b) HPSC.

SEM images of uncoated, epoxy coated and polymer coated samples before and after the immersion test of 60 days have been shown in Figure 23 and 24 respectively. These images clearly show the formation of large pits on the surface of mild steel after immersion. These pits and cracks were developed during the corrosion of mild steel in $\mathrm{NaCl}$ medium.
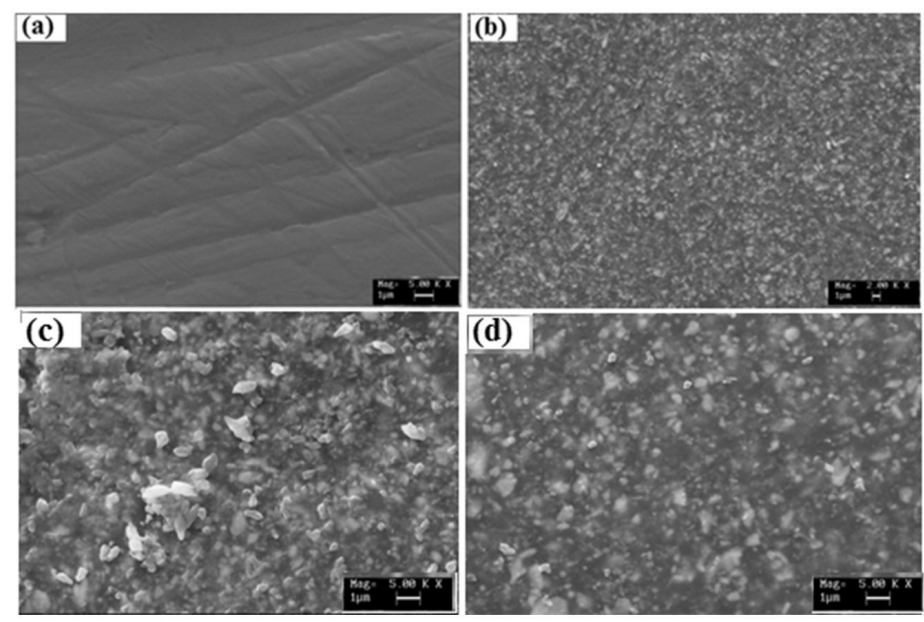

Figure 23. SEM micrographs of mid steel electrode (a) blank (b) epoxy coated (c) PANI coated (d) HPSC coated before immersion.

When epoxy coated mild steel sample was immersed in the acidic medium for 60 days, detachment of coating from mild steel substrate have been observed. The pits were also appeared on the metal surface as shown in Figure 24. In the case PANI coated sample, few pits still appeared on mild steel surface. While, HPSC coated mild steel samples did not show any cracks and pits on the metal surface. No detachment of coating from mild steel substrate was also observed after the immersion of these samples in $3.5 \% \mathrm{NaCl}$ medium for 60 days of immersion indicating strong adherence of HPSC composite to the mild steel substrate and it is resistant to corrosion in aqueous $3.5 \% \mathrm{NaCl}$ medium. 

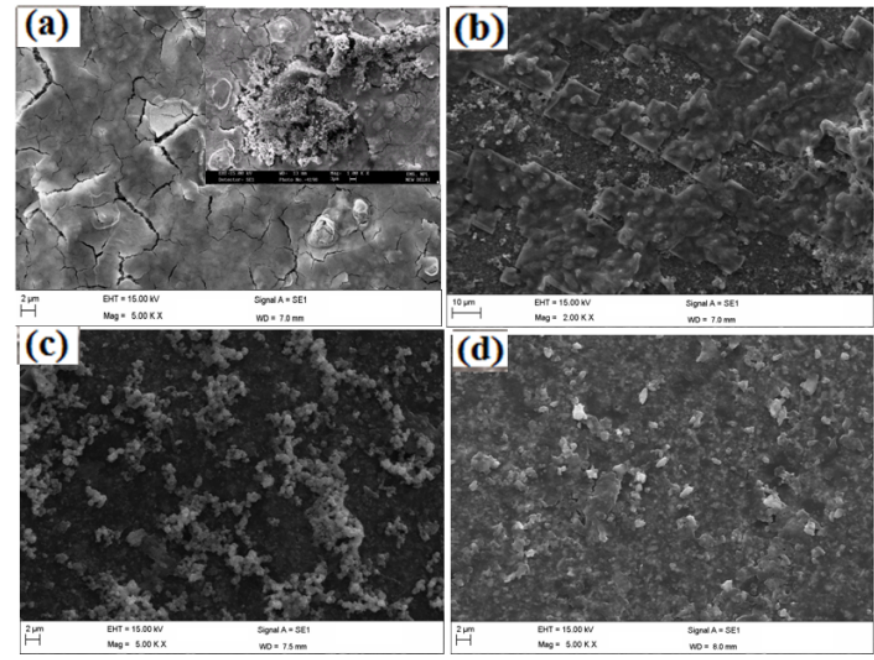

Figure 24. SEM micrographs of mid steel electrode (a) blank (b) epoxy coated (c) PANI coated (d) HPSC coated after immersion.

It was found that the HPSC content has a great influence on the anticorrosive performance of the coating. The corrosion protection effect of HPSC coated mild steel sample improved slowly when HPSC content in epoxy formulation increases from 1.5 to $3.0 \mathrm{wt}$. \% Afterward, an excellent corrosion protection effect appears at $6.0 \mathrm{wt}$ \% loading of HPSC content in epoxy resin.

\subsection{Mechanism of corrosion protection of $\mathrm{PANI}^{-\mathrm{SiO}_{2}}$ nanocomposites}

The corrosion studies show that the PANI-SiO ${ }_{2}$ nanocomposites containing coating showed better corrosion protection as compared to PANI coating which may be due to the redox property and uniform distribution of PANI in the coating containing PANI-SiO ${ }_{2}$ nano-composites. Earlier studies [63-64] have shown that the redox property of PANI coating on metal surface plays an important role to protect the metal by passivating the pin holes. Corrosion protection of metals occurs via reduction of PANI-Emeraldine salt (PANI-ES) to PANI-Leucosalt (PANI-LS) with the concomitant release of phosphate dopant [19]. Phosphate ions help to form passive film on mild steel at the defect. PANI-LS is assumed to undergo a subsequent re-oxidation by dissolved oxygen to PANI-ES. Due to this cyclic reaction, the coating containing PANI is able to offer higher corrosion protection. However, in case of PANI$\mathrm{SiO}_{2}$ nano composites containing coating, these composites have a dual protection mechanism; forming a passive layer and simultaneously acting as a physical barrier to avoid chloride ion penetration. Moreover, it acts as a barrier between metal surface and corrosive environment. Entrance of water and corrosive ions on the metal surface causes the defects in the paint coating and therefore the protective property of the coating is decreased. Due to uniform distribution of PANI, the possibility of forming uniform passive layer on the mild steel surface is more since PANI has been shown to protect the mild steel surface by passive 
film formation. Furthermore, powder coating technique also plays an important role for achieving high quality, durable and good anticorrosive coatings.

Corrosion protection property of these coating may also be attributed to the PSC/HPSC content in epoxy resin which can react with epoxy to form highly adherent, dense and non porous polymer film on the mild steel surface. On the other hand, presence of $\mathrm{SiO}_{2}$ nanoparticles entrapped in PANI chain provide the reinforcement to PANI chain which reduce the degradation of polymer chain in corrosive condition.

\section{Antistatic performance of the conducting polymers nanocomposites based on nanotubes of poly (aniline-co-1-amino-2-naphthol-4-sulphonic acid)/LDPE composites}

\subsection{Introduction}

Electrostatic charge dissipation has become an important issue within the electronic components such as data storage devices, chips carriers and computer internals. Antistatic protection is also required for parts where relative motion between dissimilar materials occurs [65] like weaving machine arms, airplane tyres etc. Conventional polymers commonly being used for packaging of various electronic equipments but due to their inherent electrical insulating nature, these polymers failed to dissipate the static or electrostatic charge. The generation of static electricity on the materials leads to a variety of problems in manufacturing and consumer use. Moreover, electronic components are susceptible to damage from electrostatic discharge. Thus the challenge is to convert inherently insulating thermoplastic to a product that would provide an effective antistatic material. Various attempts have been made to achieve the antistatic polymers with retained mechanical properties such as addition of antistatic agents [66], conducting additives [67] and fillers like carbon powder [68] and carbon nanotubes [69] etc. The electrical conductivity of the polymeric material depends on the amount, type and shape of the conducting filler [70]. According to electronic industries association (EIA) standards, in ESD protected environments, the optimal surface conductivity should be in the range of $10^{-6}$ to $10^{-10} \mathrm{~S} / \mathrm{cm}$. However the functioning of antistatic agents is critically dependent on the relative humidity [71] whereas the metal and carbon filled materials suffer from the problems like bleeding and poor dispersion [72]. Moreover, it has been observed that carbon black loaded static controlling materials usually contain 15-20\% carbon black. The addition of carbon black at higher concentrations showed a negative effect on the proccessability of the compound and mechanical properties such as increase in melt viscosity and decrease in impact resistance. Use of conducting blends and composites with conventional polymers as an electrostatic charge dissipative material is one of the promising application of conducting polymers which combines the mechanical properties of conventional polymers and electrical properties of conducting polymers. Polyaniline is one of the most promising intrinsically conducting polymer (ICPs) because of its good environmental stability and high electrical conductivity, which can be reversibly controlled by a change in the oxidation state and protonation of the imine nitrogen groups. Blending of polyaniline 
with conventional polymers like polypropylene, ABS, LDPE etc. can also be used to improve the proccessability of polyaniline creating new materials with specific properties for the desired application at low cost that can also be used for different applications like electromagnetic shielding and corrosion prevention where conductivity, proccessability and mechanical properties of the materials are of the primary importance. Hence desired properties of conducting polymers can be enhanced by mixing it with a polymer that has good mechanical properties and the unique combination of electrical and mechanical properties of conducting copolymers blends with insulating polymers seems to have great potential for their use in many applications [73-75].

\section{Antistatic measurements}

Antistatic or electrostatic charge dissipative performances of blends of conducting polymers were measured by Static decay meter, John Chubb Instrument and Static Charge Meter. The detailed method is given below.

\subsection{Static decay meter}

Static decay meter is very useful device for measurement of static decay time of the conducting polymer blends in the form of injection moulded sheets and blown film. The samples of conducting copolymer blends (LDPE/conducting copolymer) were cut in to the $15 \times 15 \mathrm{~cm}^{2}$ blown film and was used for measurement of static decay time on Static Decay Meter by measuring the time on applying a positive voltage of $5000 \mathrm{~V}$ and recording the decay time on going down to $500 \mathrm{~V}$. Similarly the static decay time was measured by applying a negative voltage of $5000 \mathrm{~V}$. Here, these measurements were carried out on Static Decay Meter; model 406D, Electro-tech System, Inc., USA. The model 406D Static Decay Meter is designed to test the static dissipative characteristics of material by measuring the time required for charge test sample to discharge to a known, predetermined cut-off level. Three manually selected cut-off threshold at 50\%,10\% and 1\% of full charge are provided and samples are charged by an adjustable 0 to $\pm 5 \mathrm{kV}$ high voltage power supply.

\subsection{John Chubb Instrument}

John Chubb Instrument (JCI 155 v5) charge decay test unit is a compact instrument for easy and direct measurement of the ability of materials to dissipate static electricity and to assess whether significant voltage will arise from practical amount of charge transferred to surface [76]. The JCI 176 Charge Measuring Sample Support (connected with JCI 155 v5) provides a convenient unit to support film and layer materials (and also powder and liquids). The samples of conducting copolymer blends (LDPE/conducting copolymers) i.e. 45 × $54 \mathrm{~mm}^{2}$ blown film were used for measurement of static decay time on John Chubb Instrument (Model JCI $155 \mathrm{v} 5)$ by measuring the time on applying the positive as well as negative high corona voltage of $5000 \mathrm{~V}$ on the surface of material to be tested and recorded the decay time at $10 \%$ cutoff. A fast response electrostatic field meter observes the voltage received on the surface of sample and measurements were to observe how quickly the voltage falls as the charge is 
dissipated from the film. The basic arrangement for measuring the corona charge transferred to the test sample during corona charge decay measurements is shown in Figure 24. Charge is measured as a combination of two components-'conduction charge' and 'induction charge'. The 'conduction' component is that which couples directly to the sample mounting plates within the time of application of corona charging and the time for the plate carrying the corona discharge points to move away.

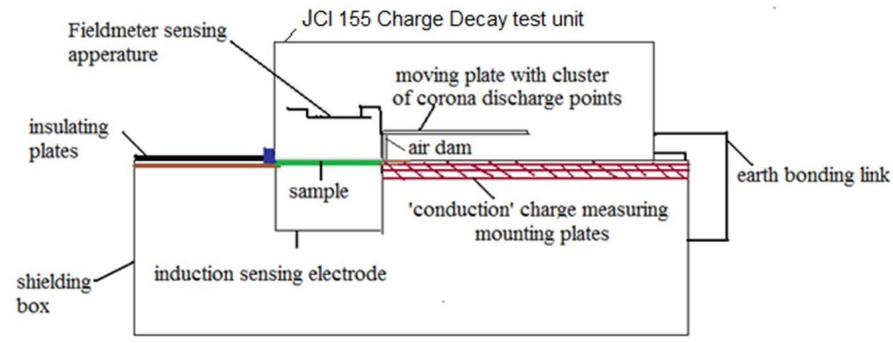

Figure 25. Schematic arrangement of JCl 155 v5 on JCl 176 charge measuring sample support.

The 'inducting' relates to the charge that has been deposited but has not coupled out directly to the mounting plates and the total charge transferred to the sample can be measured as:

$$
\mathrm{Q}_{\text {total }}=\mathrm{Q}_{\text {(conduction) }}+\mathrm{f} * \mathrm{Q}_{\text {(induction) }}
$$

where the factor ' $\mathrm{f}$ ' is actually close to 2.2. This factor can be determined experimentally. The film and layer polymeric samples are easily mounted in the JCI 176 between the two hinged flat metal plates. The aperture in the sample mounted plates, to which the conduction charge is measured, are $5 \mathrm{~mm}$ larger all round than the $45 \times 54 \mathrm{~mm}^{2}$ test aperture of the JCI 155 . The JCI 155 Charge Decay Test unit sits on top of the JCI 176 Charge Measuring Sample Support into the recess between the boundary edges. The measurements are recorded in the form of graphs (ESD/ JCI-graphs) which show the decay of surface voltage with respect to decay time.

\section{Synthesis of poly(aniline-co-1-amino-2-naphthol-4-sulphonic acid)}

Copolymers of 1-amino-2-naphthol-4-sulphonic acid (ANSA) and aniline of varying composition (i.e. by varying the co-monomer feed compositions in the initial feed) were synthesised by chemical oxidative polymerization in the presence of PTSA. Polymerization was initiated by the drop wise addition of ammonium persulphate solution (0.1 M APS in distilled water). The polymerization was carried out at a temperature of $0 \mathrm{C}$ for a period of 4-6 h. Their copolymers were synthesised by varying the molar ratio of co-monomers in the initial feed. The synthesized copolymers were isolated from reaction mixture by filtration and washed with distilled water to remove oxidant and oligomers.

PTSA doped copolymers of aniline and ANSA (poly(AN-co-ANSA) in 80:20 molar ratio and 50:50 molar ratio is abbreviated as PANSA2-PTS and PANSA5-PTS respectively whereas PTSA doped polyaniline is abbreviated as PANI-PTS. 


\section{Preparation of LDPE-Conducting Copolymer Film}

Composites of copolymers with LDPE were prepared by melt blending method. Required amount of LDPE and copolymers were loaded in internal mixer for 20-30 minutes at around $60 \mathrm{rpm}$. Blending of copolymers with LDPE was carried out in twin-screw extruder at the temperature range from $140-150^{\circ} \mathrm{C}$ by melt mixing method. The blown film of the copolymer/LDPE composite was made by Haake Blown Film instrument at the temperature range of $160^{\circ} \mathrm{C}$ where speed of screw was maintained at $40 \mathrm{rpm}$. PTSA doped copolymers of aniline and ANSA (poly(AN-co-ANSA) in 80:20 and 50:50 molar ratio blended with LDPE is abbreviated as PANSA2-PTS/LDPE and PANSA5-PTS/LDPE respectively.

\section{Characterization}

\subsection{Characterization of PTSA doped PANI and copolymers of AN and ANSA}

ANSA is a tri-functional monomer having three functional groups (i.e. $-\mathrm{NH}_{2},-\mathrm{OH}$ and $\mathrm{SO}_{3} \mathrm{H}$ ) along with two fused benzene rings.

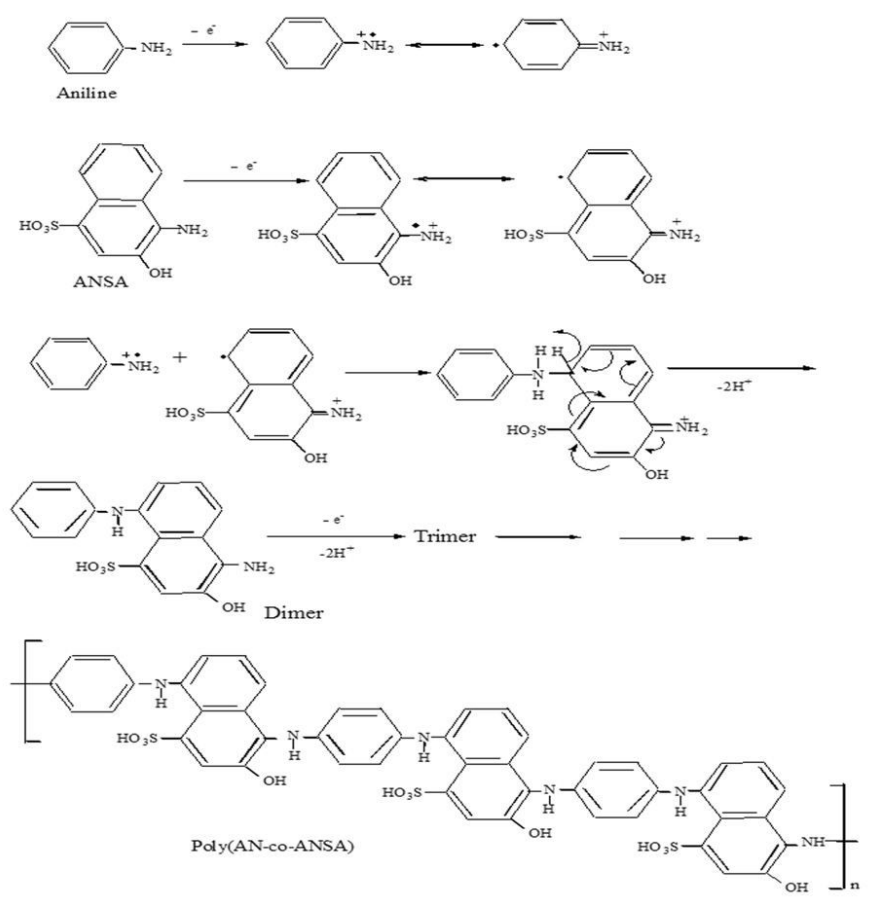

Figure 26. Proposed mechanism during the copolymerization of aniline and ANSA in the presence of p-toluene sulphonate (Reproduced with permission from Ref. 80, Copyright 2009 John Wiley \& Sons). 
This monomer can be copolymerized with aniline to give different materials and it has been observed that the participation of functional groups $\left(-\mathrm{NH}_{2}\right.$ and $\left.-\mathrm{OH}\right)$ in the polymerization depends upon the reaction conditions. It is proposed that polymerization of ANSA in the presence of PTSA occurred selectively through $-\mathrm{NH}_{2}$ group (figure 26) as confirmed by structural characterization (FTIR and NMR spectroscopy) [77].

\subsubsection{Morphological Characterization}

Figure 27 shows SEM micrographs of PTSA copolymers of ANSA and AN. PANI-PTS show a globular sponge like structure (Figure 27a) and morphology changed with varying copolymer composition. PTSA doped copolymers of aniline and ANSA exhibit hollow tube like morphology. The use of 1-amino-2-naphthol-4-sulphonic acid as a comonomer as well as nature of external dopant played an important role for achieving the tubular morphology. In case of PTSA doped copolymers of aniline and ANSA in ratio of 80:20 (PANSA2-PTS), the globular morphology of the resultant copolymer tend to change to the tube forms (Figure $27 \mathrm{~b}$ ).
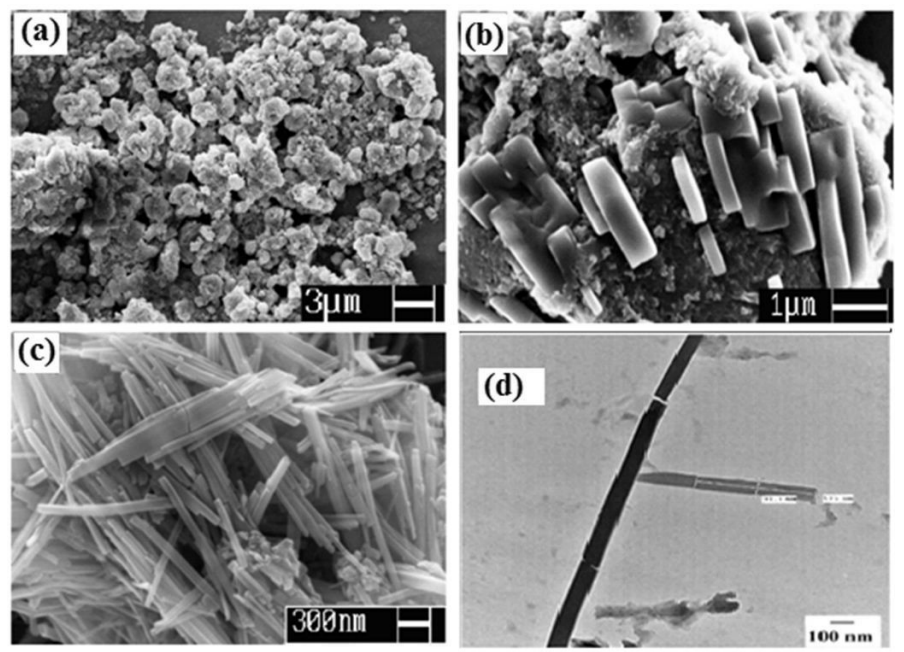

Figure 27. SEM image of (a) PANI-PTS (b) PANSA2-PTS; (c) PANSA5-PTS and (d) TEM image of PANSA5-PTS (Reproduced with permission from Ref. 77, Copyright 2009 John Wiley \& Sons).

However, well defined tubes were formed when molar ratio of aniline/ANSA was 50:50 in the presence of PTSA (Figure 27c). The difference in the morphology between polyaniline and its copolymers with ANSA may be related to the different reactivities of the two monomers, nature of reaction media and reaction route.

TEM image of PTSA doped copolymer of aniline and ANSA in 50:50 molar ratios (Figure 26d) shows that these tubes are hollow with outer diameter of $80-90 \mathrm{~nm}$. 


\subsubsection{Conductivity}

Room temperature conductivity values of PTSA doped samples are summarised in Table 5, which reveals that the room temperature conductivity of PANI-PTS was found to be better than PTSA doped copolymers.

\begin{tabular}{lcc}
\hline Sample Designation & $\begin{array}{c}\text { Room temperature } \\
\text { conductivity }(\mathbf{S} / \mathbf{c m})\end{array}$ & Thermal stability $\left({ }^{\circ} \mathbf{C}\right)$ \\
\hline PANI-PTS & 1.72 & 200 \\
\hline PANSA2-PTS & $4.48 \times 10^{-1}$ & 195 \\
\hline PANSA5-PTS & $1.98 \times 10^{-2}$ & 188 \\
\hline
\end{tabular}

Table 5. Room temperature conductivity and thermal stability.

On increasing the molar ratio of ANSA in copolymer, conductivity tends to decrease accordingly due to the presence of three functional groups in ANSA unit which exerted a strong steric effect on the doping process hence induces additional deformation along the polymer backbone.

\subsection{Characterization of LDPE/Conducting Polymer composite film}

\subsubsection{Thermal Properties}

These copolymers (PANSA2-PTS/PANSA5-PTS) can be melt blended with conventional polymers like LDPE. Figure 28 shows the TG traces of blown films of PTSA doped copolymer/ LDPE composites. The degradation temperature of pure LDPE blown film was around $400^{\circ} \mathrm{C}$. Thermal stability of the blown film of copolymer/LDPE blends (0.5-1.0 wt \% loading) was also found to be same as LDPE.

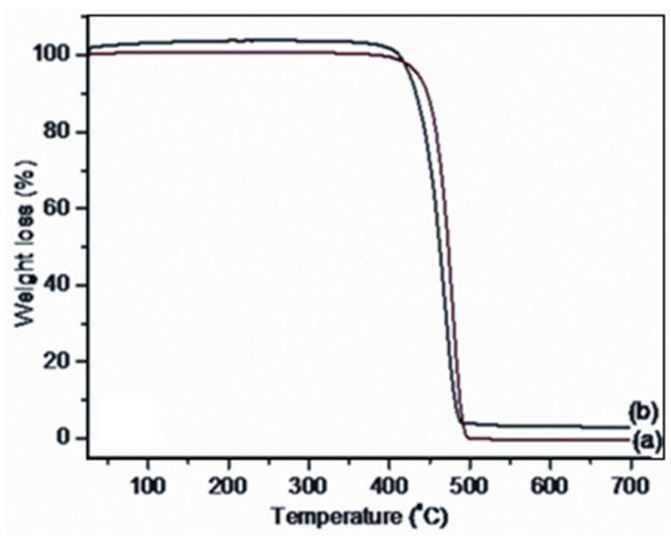

Figure 28. TG traces of (a) LDPE/PANSA2 -PTS and (b) LDPE/PANSA5-PTS films at 1.0 wt. \% loading. 


\subsubsection{Mechanical properties}

The mechanical properties of PTSA doped poly (AN-co-ANSA)/LDPE film was measured and the results are summarised in the Table 6. In case of pure LDPE film, the tensile modulus and yield stress were $141 \mathrm{MPa}$ and $16.3 \mathrm{MPa}$ respectively. However, the inclusion of poly (AN-co-ANSA) in LDPE led to decrease in both tensile modulus and yield stress depending upon the molar ratio of ANSA in the copolymer chain as well as type of dopant.

\begin{tabular}{lclllll}
\hline $\begin{array}{l}\text { Sample } \\
\text { Designation }\end{array}$ & $\begin{array}{l}\text { Loading of } \\
\text { copolymers In } \\
\text { LDPE (wt. \%) }\end{array}$ & $\begin{array}{l}\text { Tensile } \\
\text { modulus } \\
\mathbf{( M P a})\end{array}$ & $\begin{array}{l}\text { Yield } \\
\text { Stress } \\
\mathbf{( M P a )}\end{array}$ & $\begin{array}{l}\text { Ultimate } \\
\text { elongation } \\
\mathbf{( \% )}\end{array}$ & $\begin{array}{l}\text { Conductivity } \\
\text { of LDPE/ } \\
\text { copolymers } \\
\text { film (S/cm) }\end{array}$ \\
\hline LDPE & 1.0 & 141 & 16.3 & 187 & "/10-12 \\
\hline LDPE/PANSA2-PTS & 1.0 & 129 & 12.1 & 176 & $1.28 \times 10^{-6}$ \\
\cline { 2 - 7 } & 0.5 & 134 & 13.1 & 180 & $2.22 \times 10^{-9}$ \\
\hline LDPE/PANSA5-PTS & 1.0 & 120 & 10.3 & 166 & $8.18 \times 10^{-7}$ \\
\cline { 2 - 7 } & 0.5 & 131 & 12.3 & 171 & $4.13 \times 10^{-9}$ \\
\hline
\end{tabular}

Table 6. Mechanical and electrical properties of LDPE films in the absence/presence of conducting copolymers.

In the case of film prepared by composites of LDPE/conducting copolymer (99/1 w/w or 99.5/0.5 w/w), tensile modulus, yield stress and \% elongation decreased (Table 6). Tensile modulus decreased from $141 \mathrm{MPa}$ (LDPE) to $120 \mathrm{MPa}$ (LDPE/PANSA5-PTS) at a concentration of $1.0 \% \mathrm{w} / \mathrm{w}$. Yield stress also decreased for $16.3 \mathrm{MPa}$ (LDPE) 10.3 MPa (LDPE/ PANSA5-PTS). Similarly, the ultimate elongation also decreased in the same manner.

At a loading of $0.5 \%(\mathrm{w} / \mathrm{w})$ of PTSA doped copolymers in LDPE, tensile modulus also decreased from $134 \mathrm{MPa}$ (for PANSA2-PTS/LDPE) to $120 \mathrm{MPa}$ (for PANSA5/LDPE). Similarly, 0.5 wt. \% loading of PTSA doped copolymers with LDPE, yield stress reduced from 13.1 $\mathrm{MPa}$ in case of PANSA2-PTS/LDPE to $12.3 \mathrm{MPa}$ for PANSA5-PTS/LDPE film and the ultimate elongation was also found to be $180 \%$ and $171 \%$ for PANSA2-PTS/LDPE and PANSA5-PTS/LDPE composite films respectively. Hence, the mechanical strength of PTSA doped poly(AN-co-ANSA)/LDPE blended films was found to be better in case $0.5 \mathrm{wt} \%$ loading of copolymers than that of 1.0 wt. \% loading. Moreover, it has also been observed that mechanical properties of PTSA doped copolymers-LDPE film were different from that of self doped copolymers-LDPE films. Mechanical strength of the poly(AN-co-ANSA)/LDPE composites decreased with increasing the molar ratio of ANSA in the copolymer (Table 6).

\subsubsection{Electrical Properties}

Room temperature conductivity values of PTSA doped copolymers/LDPE composite film are summarised in Table 6 . The room temperature conductivity of copolymers of aniline with ANSA decreased from $4.48 \times 10^{-1}$ to $1.98 \times 10^{-2} \mathrm{~S} / \mathrm{cm}$ depending on the molar ratio of 
ANSA in the copolymer feed and type of dopant. The conductivity values copolymers were found to be $4.48 \times 10^{-1} \mathrm{~S} / \mathrm{cm}$ and $1.98 \times 10^{-2} \mathrm{~S} / \mathrm{cm}$ for PANSA2-PTS and PANSA5-PTS respectively (Table 5). On blending with LDPE at $1.0 \mathrm{wt} \%$, conductivity value decreased from 1.28 $\times 10^{-6} \mathrm{~S} / \mathrm{cm}$ to $8.18 \times 10^{-7} \mathrm{~S} / \mathrm{cm}$ respectively. When the loading level of copolymers with LDPE reduced from $1.0 \mathrm{wt} \%$ to $0.5 \mathrm{wt} \%$, the conductivity of the resultant composites decreased. $0.5 \%(\mathrm{w} / \mathrm{w})$ loading of LDPE films based on PANSA2-PTS and PANSA5-PTS had conductivity value in the order of $2.22 \times 10^{-9} \mathrm{~S} / \mathrm{cm}$ and $4.13 \times 10^{-9} \mathrm{~S} / \mathrm{cm}$ respectively.

\subsubsection{Morphological Characterization}

Figure 29 show the SEM images of LDPE films in the presence of PTSA doped copolymers at 0.5 wt. \% loading. When these copolymers were blended with LDPE, the copolymer domains were found to disperse in the LDPE matrix as evident by the appearance of tubes and needle like granules in the LDPE matrix (Figure 29). In addition, the formation of the conducting path is evident and agrees with the results relating to electrical conductivity of the composites. In copolymer composites (matrix and dispersed phase), the level of interaction between the two components and mode of dispersion in the matrix, influence the electrical and mechanical properties of the composites [79]. The SEM micrographs of the LDPE/ copolymer film showed two different phases i.e. conducting copolymer and non conducting matrix (LPDE). Interconnection of conducting phase in the non-conducting matrix creates a conducting path along the LDPE matrix.

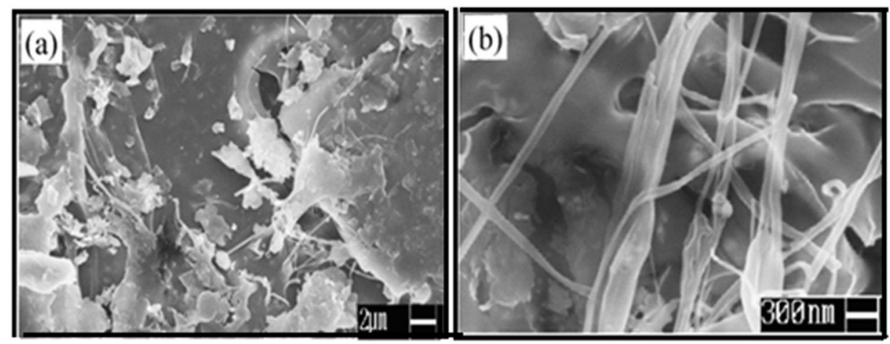

Figure 29. SEM images of (a) PANSA2-PTS/LDPE, (b) PANSA5-PTS/LDPE composite films at 0.5\% (w/w) loading (Reproduced with permission from Ref. 77, Copyright 2009 John Wiley \& Sons).

Moreover, it has also been observed that the conduction mechanism and transportation of charge carrier in the blends depend on the loading level and mode of dispersion of the conducting materials. PANSA5-PTS nanotubes at $0.5 \mathrm{wt}$ \% loading with LDPE, the surface conductivity was found to be in the order of $10^{-9} \mathrm{~S} / \mathrm{cm}$, which is suitable for their use in ESD protection applications.

Hence, it may be presumed that when the sufficient amount of conducting material is loaded in the polymer matrix, the conducting particles get closer and form linkage which makes an easy path for conduction of charge carrier throughout the blend which shows sufficient loading and good dispersion of conducting material in the polymer ma- 
trix (i.e. LDPE). While in the case of very low loading of conducting material in the polymer matrix, the gap between conducting particles in the polymer matrix is large with the result that no conduction path in the blend.

Hence, the conductivity of films based on blends depends on the morphology of conducting material. The nanotubular or fibre like morphology of conducting materials which form a network in the whole blend facilitate the conduction of charge carrier through the continuous structure of the chain of conducting material in the insulating matrix at very low loading of conducting material in the insulating matrix.

\section{Antistatic Behaviour of LDPE/Copolymer Film}

The results of static decay time on application of positive/negative voltage of $5000 \mathrm{~V}$ and recording the decay time on going down to $500 \mathrm{~V}$ are summarised in Table 7 . It was observed that blank LDPE film shows a static decay time of $120.1 \mathrm{sec}$. It decreased upon addition of copolymer and was found to be dependent on the amount of copolymer. LDPE film having $1.0 \%(\mathrm{w} / \mathrm{w})$ and $0.5 \%(\mathrm{w} / \mathrm{w})$ of PANSA2-PTS showed a decay time of $0.1 \mathrm{sec}$. and $1.4 \mathrm{sec}$. respectively at $10 \%$ cut-off. However, the PANSA5-PTS/LDPE film showed a static decay time of $0.8 \mathrm{sec}$. at a loading of $0.5 \mathrm{wt}$. \% and $0.2 \mathrm{sec}$. at $1.0 \mathrm{wt} \% \%$ loading [80]. Any material which showed a static decay time less than $2.0 \mathrm{sec}$ passes the criteria for its use as antistatic material. Based on the above observations, we can say that LDPE film prepared by blending of conducting copolymer based on AN and ANSA at $1.0 \% \mathrm{w} / \mathrm{w}$ loading, can be used as an effective antistatic film. Similar measurements were recorded with copolymer composite film with a cut-off value of $50 \%$ and the results are summarised in Table 7 .

\begin{tabular}{|c|c|c|c|c|c|}
\hline \multirow[t]{2}{*}{ Sample Designation } & \multirow{2}{*}{$\begin{array}{l}\text { Loading of } \\
\text { copolymers in } \\
\text { LDPE (wt. \%) }\end{array}$} & \multicolumn{2}{|c|}{$\begin{array}{c}\text { Static decay time (at } 10 \\
\% \text { Cut off) (Sec.) }\end{array}$} & \multicolumn{2}{|c|}{$\begin{array}{l}\text { Static decay time (at } 50 \\
\% \text { Cut off) (Sec.) }\end{array}$} \\
\hline & & $\begin{array}{l}\text { Positive } \\
\text { voltage }\end{array}$ & $\begin{array}{l}\text { Negative } \\
\text { voltage }\end{array}$ & $\begin{array}{l}\text { Positive } \\
\text { voltage }\end{array}$ & $\begin{array}{l}\text { Negative } \\
\text { voltage }\end{array}$ \\
\hline Blank LDPE & -- & 120.1 & 110.8 & 94.9 & 93.1 \\
\hline \multirow[t]{2}{*}{ LDPE/PANSA2-PTS } & 1.0 & 0.1 & 0.1 & 0.01 & 0.01 \\
\hline & 0.5 & 1.4 & 1.5 & 0.2 & 0.3 \\
\hline \multirow{2}{*}{$\begin{array}{l}\text { LDPE/PANSA5-PTS } \\
\text { nanocomposites }\end{array}$} & 1.0 & 0.2 & 0.1 & 0.01 & 0.01 \\
\hline & 0.5 & 0.8 & 0.9 & 0.1 & 0.1 \\
\hline
\end{tabular}

Table 7. Antistatic behaviour of LDPE/copolymer composite films.

Static decay measurements were also performed on John Chubb Instrument (JCI 155 v5) charge decay test unit by measuring the time on applying the positive as well as negative high corona voltage of $5000 \mathrm{~V}$ on the surface of material to be tested and recorded the decay time at $10 \%$ cut off. A fast response electrostatic field meter observes the voltage received 
on the surface of sample and measurements were to observe how quickly the voltage falls as the charge is dissipated from the film. Graphs obtained from these experiments have been shown in the Figure 30, which show the decay of surface voltage and decay time.

The surface voltage and surface charge received by the materials depend on nature of materials. When positive or negative high corona voltage (i.e. $5000 \mathrm{~V}$ ) was applied to the surface of the material, only a limited amount of voltage was received by the blend depending on the nature of materials. When high corona voltage was applied on the surface of insulating material, only some voltage was drained away and greater amount of voltage were retained on its surface. This surface voltage decays at particular time. Moreover, the surface charge received by the blends was also calculated during the experiment.
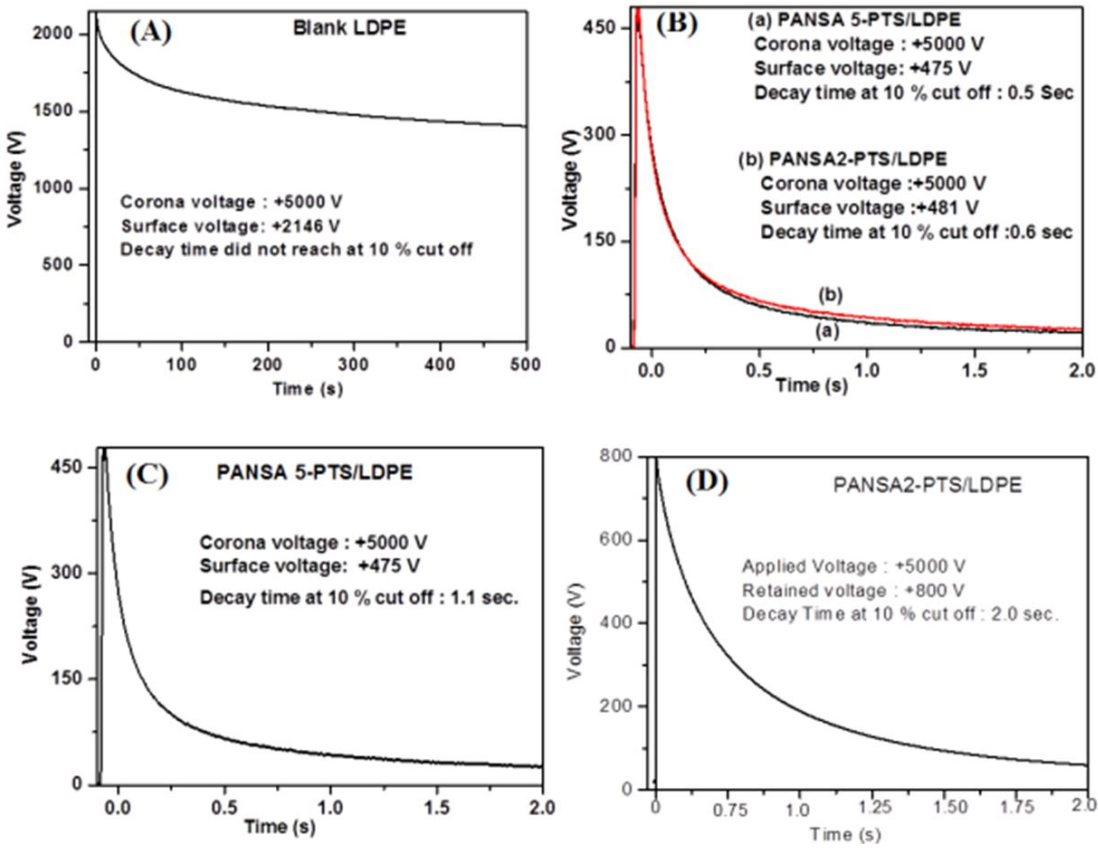

Figure 30. ESD-graphs of LDPE film in the presence of AN-ANSA copolymers (A) blank LDPE film, (B) Copolymer/LDPE nanocomposites film at 1.0 wt.\% loading, (C) PANSA5-PTS at 0.5 wt. \% loading and (D) PANSA2-PTS at 0.5 wt. \% loading (Reproduced with permission from Ref. 77, Copyright 2009 John Wiley \& Sons).

Hence the charge retention capability of conducting materials was found to be very low thus they quickly dissipate this surface charge. The static decay time of blank LDPE film was found to be very high on applying the positive and negative corona voltage of 5000 $\mathrm{V}$. The peak at $2146 \mathrm{~V}$ indicate that the LDPE film has received $2146 \mathrm{~V}$ at the surface corresponding to $55.79 \mathrm{nC}$ of static charge, which get dissipated very slowly and was not found to be able to dissipate it up to $10 \%$ cut off as shown in the Figure 30A. Due to insulating nature of the material, lot of charges were found to be retained on the sur- 
face of LDPE film. Blending of 1.0 wt. \% of conducting copolymer with LDPE, decreases the charge retention capability by reducing the decay time. In case of PANSA5-PTS/ LDPE film at $1.0 \mathrm{wt}$. \% loading of PANSA 5-PTS in LDPE, the peak started at $475 \mathrm{~V}$ on applying the voltage of $+5000 \mathrm{~V}$, which indicates that the voltage received at the surface is only $475 \mathrm{~V}$ corresponding to $9.51 \mathrm{nC}$ of charges which dissipated quickly, around 0.5 sec., at $10 \%$ cut off as shown in the Figure 30B (curve a).

Similar trend has been found for negative polarity charging at the same corona voltage. In the case of film samples prepared by blending of $0.5 \mathrm{wt}$. \% PANSA5-PTS with LDPE, $475 \mathrm{~V}$ of voltage and $10.45 \mathrm{nC}$ of charges were received by its surface which was dissipated up to $10 \%$ cut off in $1.1 \mathrm{sec}$ (Figure 30C). on the other hand, LDPE + 0.5 wt. \% PANSA2-PTS showed $+800 \mathrm{~V}$ of surface voltage received by the composite on applying the voltage of $+5000 \mathrm{~V}$ which showed the large decay time (2.0 sec at $10 \%$ cut off). Similar behaviour was observed at negative polarity charging. Hence the ESD protection performance of the conducting blends not only depends on the loading level of conducting materials but also depend on the morphology and dispersion of conducting materials in the polymer matrix. Nanocomposites based on LDPE/PANSA5-PTS film showed better ESD performance as compared to LDPE/PANSA2-PTS film.

\section{Conclusions}

PANI/SiO $\mathrm{S}_{2}$ nanocomposites were prepared by chemical oxidation polymerization of aniline and $\mathrm{SiO}_{2}$ by using ammonium persulfate (APS) as an oxidant in the presence of phosphoric acid/PFOA medium. FTIR, UV-Visible, cyclic voltammetry and SEM techniques confirmed the interaction of PANI with $\mathrm{SiO}_{2}$ particles. The excellent corrosion protection performance by PSC coated mild steel could be due to the strong adherence of polymer film which uniformly covers the entire electrode surface as has shown by the surface morphology. The corrosion current densities were lowered several orders of magnitude with these coatings. The coating had good protective efficiency which increased with increasing the loading of PSC to the maximum of $99 \%$ at $6.0 \mathrm{wt}$.\% loading and reduced to about $89.93 \%$ after 60 days of immersion in highly corrosive environment confirming the improved coating performance. Weight loss method also revealed that PSC coated samples showed very low weight loss as well as negligible corrosion rate as compared to PANI coated samples at same immersion time, which indicates the better protection and adhesion of PSC onto the mild steel surface as compared to PANI in strong acidic condition.

In order to improve anticorrosion performance of iron in $3.5 \% \mathrm{NaCl}$ aqueous medium, preparation of highly hydrophobic polyaniline- $\mathrm{SiO}_{2}$ nano-composites (HPSC) have also been carried out by chemical oxidation polymerization. Water repellent property of the PSC has been developed by using fluorinated dopant i.e. perfluoro-octanoic acid (PFOA). HPSC coating were evaluated for protection of mild steel from corrosion in $3.5 \% \mathrm{NaCl}$ aqueous solution. Suitable coating with HPSC was formed on mild steel using epoxy resin by powder coating technique which showed the contact angle in the range of $115^{\circ}$. Corrosion pro- 
tection efficiency of mild steel coated HPSC in $3.5 \% \mathrm{NaCl}$ aqueous solution has been evaluated using Tafel Extrapolation method, surface morphology, salt spray test and weight loss methods. The results reveals that the HPSC coating showed the significant reduction in the corrosion current density reflects the better protection of mild steel in marine environment. The coating had good protective efficiency which increased with increasing the loading of HPSC to the maximum of $96 \%$ at $6.0 \mathrm{wt}$. $\%$ loading and reduced to about $93.3 \%$ after 60 days of immersion in $3.5 \% \mathrm{NaCl}$ solution confirming the improved coating performance.

Presence of $\mathrm{SiO}_{2}$ nanoparticles entrapped in PANI chain which was evident my surface morphology of composite coating, provide the reinforcement to PANI chain which reduce the degradation of polymer chain in corrosive environment. PSC/HPSC coating protect metal by dual mechanism by forming passivating layer as well as act as a physical barrier. Furthermore the role of powder coating technique for achieving high quality, durable and good anticorrosive coatings have also been explained. These studies revealed that the polyaniline$\mathrm{SiO}_{2}$ nanocomposites has excellent corrosion protection properties and it can be considered as a potential material for corrosion protection of mild steel in corrosive medium like.1.0 M $\mathrm{HCl}$ as well as $3.5 \% \mathrm{NaCl}$ solution.

In order to carry out the effective use of conducting polymer for antistatic application, nanocomposites based on poly(aniline -co- 1-amino-2-naphthol-4-sulphonic acid) (PANSA5-PTS) with low density polyethylene (LDPE) have been developed. The copolymer nanotubes of aniline and ANSA were synthesised in tosyl medium in 50: 50 molar ratio. Formation of nanotubes of copolymers was confirmed by morphological characterization using SEM and TEM. Dimension of nanotubes of PANSA5-PTS was found to be 80-90 nm. Blending of copolymers with LDPE was carried out in twin screw extruder by melt blending method by loading 0.5 wt. \% and $1.0 \mathrm{wt}$. \% of the conducting copolymer in LDPE matrix. The conductivity of the blown film of poly (AN-Co-ANSA) /LDPE composites was found to be in the range of $1.28 \times 10^{-6}$ to $4.13 \times 10^{-9} \mathrm{~S} / \mathrm{cm}$. Thermo gravimetric traces of copolymers reveals that these copolymers were thermally stable from $180^{\circ} \mathrm{C}$ to $195^{\circ} \mathrm{C}$. Such copolymers were successfully melt blended with LDPE and conducting film was prepared using film blending technique. Antistatic performance of PANSA5-PTS/LDPE nanocomposite have compared with PANSA2-PTS/LDPE composites to show the influence of nanotubes in composites. Static charge measurements carried out on the films shows that no charge is present on the surface. Copolymer/LDPE composites films $(1.0 \% \mathrm{w} / \mathrm{w})$ showed static decay time in the order of 0.1 to $0.2 \mathrm{sec}$. at $10 \%$ cut-off on recording the decay time from $5000 \mathrm{~V}$ to $500 \mathrm{~V}$. When the loading level of copolymers in LDPE was reduced to $0.5 \mathrm{wt}$. \%, only the nanocomposites based on PANSA5-PTS showed better good performance to ESD protection. Better antistatic behavior shown by these copolymers at very low loading in LDPE was investigated by their nanotubular morphology. Blending of 0.5 and $1.0 \mathrm{wt}$. \% of PTSA doped copolymers with selective composition of ANSA and aniline with LDPE has a great potential to be used as effective antistatic films. The loading level, morphology of the conducting material, and its proper dispersion with insulating matrix affect the properties like surface conductivity, mechanical properties, and its performance to application for electrostatic charge dissipation. 


\section{Author details}

Hema Bhandari, S. Anoop Kumar and S. K. Dhawan

*Address all correspondence to: skdhawan@mail.nplindia.ernet.in

CSIR-National Physical Laboratory, India

\section{References}

[1] Zhua, H., Zhonga, L., Xiaoa, S., \& Gan, F. (2004). Electrochim. Acta, 49, 5161.

[2] Jones, D. A. (1992). Principles and Prevention of Corrosion, Macmillan Publishing, Chap. 1 , New York.

[3] Lacroix, J. C., Camalet, J. L., Aeiyach, S., Chane-Ching, K. I., Petitjean, J., Chauveau, E., \& Lacaze, P. C. (2000). J. Electroanal. Chem., 481, 76.

[4] Kinlen, P. J., Menon, V., \& Ding, Y. (1999). J. Electrochem. Soc., 146, 3690.

[5] Kinlen, P. J., Ding, Y., \& Silverman, D. C. (2002). Corrosion, 58, 490.

[6] de Souza, S., da Silva, J. E. P., de Torrosi, S. I. C., Temperani, M. L. A., \& Torresi, R. M. (2001). Electrochem. Solid State Lett., 4, B27.

[7] Samui, A. B., Patankar, A. S., Rangarajan, J., \& Deb, P. C. (2003). Prog. Org. Coat., 47.

[8] Dominis, A. J., Spinks, G. M., \& Wallace, G. G. (2003). Prog. Org. Coat., 48, 43.

[9] Sathiyanarayanan, S., Muthukrishnan, S., \& Venkatachari, G. (2006). Prog. Org. Coat., 55,5 .

[10] Plesu, N., Ilia, G., Pascariu, A., \& Vlase, G. (2006). Synth. Met., 156, 230.

[11] Su, S. J., \& Kuramuto, N. (2001). Synth. Met., 114, 147.

[12] Gurunathan, K., Amalnerker, D. P., \& Trivedi, D. C. (2003). Mater. Lett., 57, 1642.

[13] Sathiyanarayanan, S., Muthukrishnan, S., Venkatachari, G., \& Trivedi, D. C. (2005). Prog. Org. Coat., 53, 297.

[14] Deberry, D. W. (1985). J. Electrochem. Soc., 132, 1027.

[15] Wessling, B. (1991). Synth. Met, 41, 907.

[16] Elsenbaumer, R. L., Lu, W. K., \& Wessling, B. (1994). Seoul, Korea. Int. Conf. Synth. Met., Abstract No. APL(POL)1.

[17] Wrobleski, D. A., Benicewicz, B. C., Thompson, K. G., \& Byran, C. (1994). J. Polym. Prepr. (Am. Chem. Soc., Div. Polym. Chem.), 35, 265. 
[18] Spinks, G. M., Dominis, A. J., Wallace, G. G., \& Tallman, D. E. (2002). J. Solid State Electrochem, 6, 85.

[19] Sathiyanarayanan, S., Azim, S. S., \& Venkatachari, G. (2007). Electrochimica Acta, 52, 2068.

[20] Majumdar, G., Goswami, M., Sarma, T. K., Paul, A., \& Chattopadhyay, A. (2005). Langmuir, 21, 1663.

[21] Chowdhury, D., Paul, A., \& Chattopadhyay, A. (2005). Langmuir, 21, 4123.

[22] Feng, X. M., Yang, G., Xu, Q., Hou, W. H., \& Zhu, J. J. (2006). Macromol Rapid Commun, 27, 31 .

[23] Hasan, M., Zhou, Y., Mahfuz, S., \& Jeelani, S. (2006). Materials Science and Engineering: A, 429, 181.

[24] Li, X., Dai, N., Wang, G., \& Song, X. (2008). J Appl Polym Sci, 107, 403.

[25] Xia, H. S., \& Wang, Q. (2003). J Appl Polym Sci, 87, 1811.

[26] Zengina, H., \& Erkan, B. (2010). Polym. Adv. Technol., 21, 216.

[27] Stejskal, J., Kratochvi'l, P., Armes, S. P., Lascelles, S. F., Riede, A., Helmstedt, M., Prokes, J., \& Krivka, I. (1996). Macromolecules, 29, 6814.

[28] Al-Dulaimi, A. A., Hashim, S., \& Khan, M. I. (2011). Sains Malaysiana, 40, 757.

[29] Beck, F., Michaelis, R., Scholoten, F., \& Zinger, B. (1994). Electrochimica Acta, 39, 229.

[30] Camalet, J. L., Lacroix, J. C., Aeiyach, S., Chane-Ching, K., \& Lacaze, P. C. (1998). Synth. Met., 93, 133.

[31] Kilmartin, P. A., Trier, L., \& Wright, G. A. (2002). Synthetic Metals, 131, 99.

[32] Meneguzzi, A. A. P., Ferreira, C. A., Pham, M. C., Delamar, M., \& Lacaze, P. C. (1999). Electrochim. Acta, 44, 2149.

[33] Bhandari, H., Choudhary, V., \& Dhawan, S. K. (2010). Thin Solid Film, 519, 1031.

[34] Kinlen, P. J., Menon, V., \& Ding, Y. J. (1999). Electrochem. Soc., 146, 3690.

[35] Talo, A., Passiniemi, P., Forse'n, O., \& Yla“saari, S. (1997). Synth. Met., 85, 1333.

[36] Wessling, B., \& Posdorfer, J. (1999). Electrochim. Acta., 44, 2139.

[37] Iribarren, J. I., Armelin, E., Liesa, F., Casanovas, J., \& Aleman, C. (2006). Material and corrosion, 57, 683.

[38] Mc Andrew, T. P., Miller, S. A., Gilleinski, A. G., \& Robeson, L. M. (1996). Polym. Mater. Sci. Eng., 74, 204.

[39] Mc Hale, G., Shirtcliffe, N. J., Aqil, S., Perry, C. C., \& Newton, M. I. (2004). Phys. Rev.Lett., 93, 36102. 
[40] Shirtcliffe, N. J., Mc Hale, G., Newton, M. L., Chabrol, G., \& Perry, C. C. (2004). Adv.Mater., 16, 1929.

[41] Wu, X. F., \& Shi, G. Q. (2006). J. Phys. Chem. B., 110, 11247.

[42] Jiang, L., Zhao, Y., \& Zhai, J. (2004). Angew. Chem. Int. Ed., 43, 4338.

[43] Jiang, W. H., Wang, G. J., He, Y. N., An, Y. L., Wang, X. G., Song, Y. L., \& Jiang, L. (2005). Chem. J. Chin. Univ. (Chinese) , , 26, 1360.

[44] Han, J. T., Zheng, Y., Cho, J. H., Xu, X., \& Cho, K. J. (2005). Phys. Chem. B., 109, 20773.

[45] Soeno, T., Inokuchi, K., \& Shiratori, S. (2004). Appl. Surf. Sci., 237, 543.

[46] Li, H., Wang, X., Song, Y., Liu, Y., Li, Q. L., \& Zhu, D. (2001). Angew. Chem., 113, 1793.

[47] Wu, Y., Sugimura, H., Inoue, Y., \& Takai, O. (2002). Chem. Vap. Deposition, 8, 47.

[48] Wang, S. T., Feng, L., \& Jiang, L. (2006). Adv. Mater., 18, 767.

[49] Qu, M. N., Zhang, B. W., Song, S. Y., Chen, L., Zhang, J. Y., \& Cao, X. P. (2007). Adv. Funct. Mater., 17, 593.

[50] Pan, Q. M., Jin, H. Z., \& Wang, H. B. (2007). Nanotechnology, 18, 355605.

[51] Yabu, H., Takebayashi, M., Tanake, M., \& Shimomura, M. (2005). Langmuir, 21, 3235.

[52] Li, X., Reindhout, D., \& Crego-Calama, M. (2007). Chem. Soc. Rev, 36, 1350.

[53] Callies, M., \& Quere, D. (2005). Soft Matter, 1, 55.

[54] Ma, M. L., \& Hille, R. M. (2006). Curr. Opin. Colloid Interface Sci., 11, 193.

[55] Blossey, R. (2003). Nat. Mater., 2, 301.

[56] Anoop, Kumar. S., Bhandari, H., Sharma, C., Khatoon, F., \& Dhawan, S. K. (2012). Polymer International.

[57] Anoop, Kumar. S., Bhandari, H., Sharma, C., Khatoon, F., \& Dhawan, S. K. (2012). Polymer (Paper under process).

[58] Stern, M., \& Geary, A. (1957). J. Electrochem Soc., 104, 56.

[59] Spinks, G. M., Dominis, A. J., Wallace, G. G., \& Tallman, D. E. (2002). J. Solid State Electrochem., 6, 85.

[60] Silverstein, R. M., \& Webster, F. X. (2002). Spectrometric identification of organic compounds (sixth edition), John Wiley and Son, Wiley, India, 165.

[61] Kim, H., Foster, C., Chiang, J., \& Heegar, A. J. (1989). Synth. Metals., 29, 285.

[62] Pron, A., \& Rannou, P. (2002). Progr. Polym. Sci. ; , 27, 135.

[63] Huerta-Vilca, D., Moraes, S. R., \& Motheo, A. J. (2003). J. Braz. Chem. Soc., 14, 52. 
[64] Mc Andrew, T. P., Miller, S. A., Gilleinski, A. G., \& Robeson, L. M. (1996). Polym. Mater. Sci. Eng., 74, 204.

[65] Kusy, R. P. (1986). in Metal filled polymers, edited by S.K. Battacharya (Dekker New York, 1 .

[66] Rosner, R. B. (2001). IEEE Transaction on device and material reliability, 1.

[67] Edenbaum, J., \& Reinhold, V. N. Plastics Additives and Modifiers Handbook, New York, 615.

[68] Narkis, M., Lidor, G., Vaxman, A., \& Zuri, L. (1999). J. Electrostatics, 47, 201.

[69] Li, C., Liang, T., Lu, W., Tang, C., Hu, X., Cao, M., \& Liang, J. (2004). Composite Sci. Tech., 64, 2089.

[70] Narkis, M., Ram, A., \& Stein, A. Z. (1980). J. Appl. Polym. Sci., 25, 1515.

[71] Kobayashi, T., Wood, A., Takemura, A., \& Ono, A. (2006). Barbara Jnl. Electrostat., 64, 377.

[72] Yukishige, H., Koshima, Y., Tanisho, H., \& Kohara, T. (1996). US patent 5571859.

[73] Angelopoulos, M. (2001). Conducting polymers in microelectronics. IBM Journal of Research and Development, 45(1), 57-76.

[74] Laska, J., Żak, K., \& Prón, A. (1997). Conducting blends of polyaniline with conventional polymers. Synthetic Metals, 84(1), 117-118.

[75] Mitzakoff, S., \& De Paoli, M. A. (1999). European Polymer Journal ., 35(10), 1791-1798.

[76] Chubb, J. N. (2002). J. Electrostatics, 54, 233.

[77] Bhandari, H., Bansal, V., Choudhary, V., \& Dhawan, S. K. (2009). Polymer International, 58, 489 .

[78] Chen, S. A., \& Hwang, G. W. (1996). Macromolecules, 29, 3950.

[79] Bhandari, H. (2011). Synthesis, Characterization and Evaluation of Conducting Copolymers for Corrosion Inhibition and Antistatic Applications. PhD thesis, Indian Institute of Technology, Delhi, India.

[80] Bhandari, H., Singh, S., Choudhary, V., \& Dhawan, S. K. (2011). Polymers for Advanced Technologies, 22(9), 1319-1328.

[81] Strumpler, R., \& Glatz-Reichenbach, J. (1999). Conducting polymer composites. J. Electroceramics ., 3(4), 329-346. 